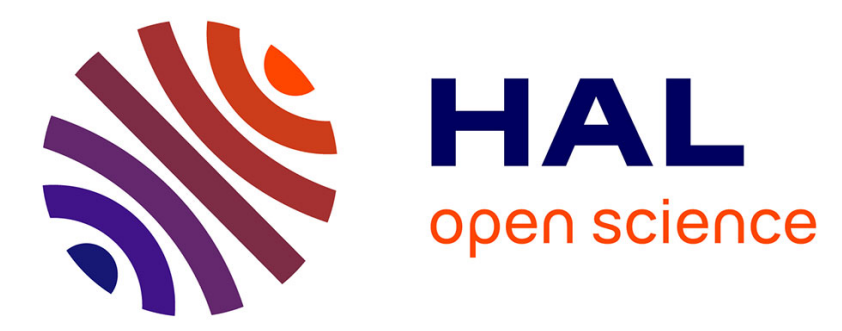

\title{
Uncertainty analysis of bimolecular reactions in Titan ionosphere chemistry model
}

Nathalie Carrasco, Odile Dutuit, Roland Thissen, Pascal Pernot, Marek Banaszkiewicz

\section{- To cite this version:}

Nathalie Carrasco, Odile Dutuit, Roland Thissen, Pascal Pernot, Marek Banaszkiewicz. Uncertainty analysis of bimolecular reactions in Titan ionosphere chemistry model. 2006. hal-00022469

\section{HAL Id: hal-00022469 \\ https://hal.science/hal-00022469}

Preprint submitted on 10 Apr 2006

HAL is a multi-disciplinary open access archive for the deposit and dissemination of scientific research documents, whether they are published or not. The documents may come from teaching and research institutions in France or abroad, or from public or private research centers.
L'archive ouverte pluridisciplinaire HAL, est destinée au dépôt et à la diffusion de documents scientifiques de niveau recherche, publiés ou non, émanant des établissements d'enseignement et de recherche français ou étrangers, des laboratoires publics ou privés. 


\title{
Uncertainty analysis of bimolecular reactions in Titan ionosphere chemistry model
}

\author{
Nathalie Carrasco, Odile Dutuit, Roland Thissen \& Pascal Pernot* \\ Laboratoire de Chimie Physique, Bât. 349 \\ UMR 8000 CNRS, Université Paris-Sud 11 \\ 91405 Orsay cedex, FrancE \\ Marek BANASZKIEWICZ \\ Space Research Centre, Bartycka 18A \\ 00-716 Warsaw, PolAnd
}

\begin{abstract}
We report about the first detailed uncertainty analysis concerning the kinetics parameters of the ion-molecule reactions included in a Titan's ionospheric chemistry model. Uncertainty propagation has been performed by Monte Carlo sampling. Different possible descriptions of the uncertainties on the rate constants are discussed and compared on the basis of our state of knowledge about ion-molecule reaction rates laboratory measurements. We propose also a new method for the treatment of

${ }^{*}$ Corresponding author. Email: pascal.pernot@lcp.u-psud.fr
\end{abstract}


branching ratios correlated uncertainties. We show that the uncertainty on branching ratios contribute significantly to the uncertainty on ion densities predicted by the chemistry model. Simulation of a mass spectrum for ionic species in Titan ionosphere at $1200 \mathrm{~km}$ of altitude and night-time chemistry has been performed and compared to the INMS mass-spectrum available on the website of the NASA (NASA/JPL/University of Michigan, 2005), corresponding to Cassini's T5 flyby. 


\section{Introduction}

Titan dense and complex atmosphere is essentially made of nitrogen and methane but also of traces of numerous hydrocarbons (Broadfoot et al., 1981; Hanel et al., 1981; Samuelson et al., 1997). This atmosphere is exposed to solar extreme ultraviolet radiations and to a flux of energetic electrons from the magnetosphere of Saturn. Nitrogen and methane ionisation initiates a complex chemistry in Titan's ionosphere between charged and neutral species producing big molecular ions. Ongoing flybys of Titan by the Cassini spacecraft are providing invaluable data on the rich chemical composition of the upper atmosphere and ionosphere. The complexity of its atmospheric chemistry makes it a challenging system for models. ${ }^{1}$ Let us note that models are very helpful to unravel the mass spectra acquired by the Ions and Neutrals Mass Spectrometer (INMS) instrument for neutral and ionic species (Waite et al., 2004, 2005).

Earlier models of Titan's ionospheric chemistry were first concerned by the major ions identified such as $\mathrm{HCNH}^{+}, \mathrm{C}_{2} \mathrm{H}_{5}^{+}, \mathrm{CH}_{5}^{+}$and $\mathrm{HCN}^{+}$(Ip, 1990; Keller et al., 1992). Keller et al. (1992) predicted the altitudes and the intensities of a peak electron density for zenith angles of 60 and 90 degrees in good agreement with Voyager data (Bird et al., 1997). Since Roboz and Nagy (1994) reported that Titan's ionosphere below $1500 \mathrm{~km}$ was chemically controlled, models evolved towards an increase in chemical species and reactions, in order to build a realistic account of the chemistry. These refinements were made possible thanks to the vast amount of laboratory data gathered over the years. Several review articles by Anicich and collaborators (Anicich, 1993; Anicich and McEwan, 1997; Anicich, 2003) report rate constants and product branching ratios for numerous bimolecular ion-molecule reactions. Fox and Yelle (1997) built a model of Titan's upper atmosphere taking into account 38 neutral species and 35 ions, involved into more than 600 chemical and physical processes. Keller et al. (1998) improved the model of Keller et al. (1992) by updating

\footnotetext{
${ }^{1} \mathrm{~A}$ recent bibliography of over 500 references as of 2005/01/09 is available online (Minard, 2005)
} 
rate constant values and by adding new ion species (51 ions in total) in order to better describe the production of heavy hydrocarbons. In all these studies, neutral species were considered as a fixed bath in Titan's ionosphere. However Keller et al. (1998) tested two different neutral atmospheres, as predicted by the neutral models of Yung et al. (1984) and Toublanc et al. (1995), and concluded that the ion densities strongly depend on the neutral atmosphere. This important correlation between ion and neutral reactivity has been accounted for by both Banaszkiewicz et al. (2000) and Wilson and Atreya (2004) who developed ion-neutral coupled models containing 33 neutrals/57 ions and 80 neutrals/33 ions, respectively.

Discrepancies between the outputs of the different models and between the outputs and available data are difficult to assess in the absence of quantified uncertainties. In particular, modelling the chemistry of planetary ionospheres involves numerous physical and chemical parameters, which values are known from laboratory measurements with non negligible uncertainty factors. These uncertainty sources should be accounted for in the modelling. Uncertainty quantification of model outputs is not a recent issue in atmospheric or space chemistry (Thompson and Stewart, 1991; Stewart and Thompson, 1996; Dobrijevic and Parisot, 1998; Dobrijevic et al., 2003; Vasyunin et al., 2004; Wakelam et al., 2005, 2006) but few systematic studies have been reported for Titan atmosphere (Hebrard et al., 2005) and none for Titan ionosphere, to our knowledge. A sensitivity test by Keller et al. (1992) revealed that a 30\% variability of ionisation cross-sections, ion-molecule reaction rates, and neutral densities produced a similar perturbation of the equilibrium ion densities. Considering that the uncertainties on the input parameters are now known to be often higher than 30\% (Anicich and McEwan, 1997; Hebrard et al., 2005) and that the uncertainties on the branching ratios of the ion-molecule reactions were not accounted for, the balance should certainly be worse. We focus in the present article on ion-molecule reactivity related uncertainties, in the case of the model of Banaszkiewicz 
et al. (2000). Uncertainty propagation is done by a Monte Carlo method.

Monte Carlo uncertainty propagation has been systematically used in recent studies (Dobrijevic et al., 2003; Vasyunin et al., 2004; Hebrard et al., 2005; Wakelam et al., 2005, 2006). This approach requires the definition of a probability density function (pdf) for the input parameters, from which one draws samples of input parameters. The probability distribution should be as representative as possible of the state of knowledge about experimental results. The 1993 and 1997 reviews by Anicich (Anicich (1993); Anicich and McEwan (1997)), on which is based the model of Banaszkiewicz et al. (2000), provide preferred values $k^{0}$ for the rate constants, usually reported with their relative uncertainty $x$, and preferred values for the corresponding branching ratios, without uncertainty.

A first point which requires a closer examination is the absence of reported uncertainties for branching ratios. Moreover, as clearly stated by Zádor et al. (2005a), it seems that the correct treatment of branching ratios as correlated parameters for more than two channels has not yet been properly addressed in the literature about uncertainty propagation in complex chemical systems. At best, the different reactive pathways of a given reaction have been treated as uncorrelated. However it is known that neglecting correlations between input parameters is a source of spurious output uncertainty (Hanson and Hemez, 2003). Hence this point is an important issue for every chemical system containing multiple channels with poorly known branching ratios. We address this issue here by using an adapted Dirichlet distribution.

The representation of rate constant uncertainty with log-normal distributions seems to be the present paradigm, regardless of the nature of the uncertainty. We would like to stress out that the appropriate type of uncertainty distribution might depend strongly on the experimental technique used or on the combination of results performed by a reviewer. Indeed, the initial and most delicate task in probabilistic uncertainty propagation is to design the probability density function in input parameters space (Helton and Davis, 2000). 
This process, called elicitation (Garthwaite et al., 2005; Jenkinson, 2005), consists in building a pdf representative of one's state of knowledge about the parameters and taking into account all pertinent information.

The present paper addresses the following questions related to uncertainty propagation:

- which type of probability density function is best adapted to represent one's state of knowledge on rate constants of ion-molecule reactions?

- how do different choices of input pdf affect uncertainty propagation results?

- how does the uncertainty propagation on the branching ratios affect the uncertainties on the outputs in such a complex chemical scheme?

Uncertainty propagation of the ion-molecule chemistry performed on the model of Banaszkiewicz et al. (2000) is applied to the estimation of ion densities. The recent publication of ion mass spectra measured by the INMS instrument on Cassini during T5 flyby (Cravens et al., 2006) motivated the extension of our results to the uncertainty propagation for ion mass spectra.

\section{Representation of uncertainty in chemistry model inputs}

Uncertainty in input parameters $\boldsymbol{\theta}$ is represented with a joint probability density function (pdf) $p(\boldsymbol{\theta} \mid I)$. As it represents a state of knowledge about the possible values of the parameters, this pdf is conditional to an ensemble of a priori information and hypotheses, noted $I$. Uncertainty propagation consists in calculating the transformation of the inputs pdf through the model $\mathbf{y}=f(\boldsymbol{\theta})$, resulting in a pdf for the outputs $p(\mathbf{y} \mid I)$. The formal 
equation for this process is (d'Agostini, 2003)

$$
p(\mathbf{y} \mid I)=\int d \boldsymbol{\theta} \delta(\mathbf{y}-f(\boldsymbol{\theta})) p(\boldsymbol{\theta} \mid I)
$$

This multidimensional integral can be evaluated by collocation methods (e.g. polynomial chaos; Isukapalli and Georgopoulos, 2001) or by Monte Carlo methods. When the number of parameters increases, collocation methods are doomed by the "curse of dimensionality". As we deal here with more than 500 parameters, we did not retain such methods.

The standard uncertainty propagation Monte Carlo algorithm consists in drawing a representative sample from the inputs pdf $p(\boldsymbol{\theta} \mid I)$, and to evaluate the value of the output(s) for every element of this sample (Helton and Davis, 2000; Helton, 2005). Statistical summaries

and approximations of the output pdf are then built from the output sample. Analysis of output uncertainty provides a basis for uncertainty analysis, i.e. identification of the contribution of each parameter (or group of parameters) to the total uncertainty, and for sensitivity analysis, i.e. identification of those parameters which are important/unimportant to the model (Saltelli et al., 2005).

\subsection{Assignment of probability distributions to uncertain input parameters}

When physical measurements are considered, the available information for assigning a probability distribution to an uncertain parameter is often limited to a published value and an associated uncertainty factor, or a set of those. The corresponding pdf is almost never specified, and has thus to be elicited. Standard procedures or good practice rules have been published for the reporting of uncertainties, as for instance in the NIST guide (Taylor and Kuyatt, 1994), but scientists rarely acknowledge their conforming to such standards. Two classes are commonly considered to qualify uncertainties (Taylor and Kuyatt, 1994): 
* statistical or "type A" uncertainties, resulting from the analysis of repeated measurements by statistical methods, and for which are reported typically a preferred value (location parameter) and an uncertainty factor (dispersion parameter);

* epistemic or "type B" uncertainties, which integrate the relevant information. There is no standard reporting scheme in this case, but a recommended approach is to report lower and upper limits.

The main rules for uncertainty reporting do also differ between scientific communities, and the elicitator has to take this global context into account. In most favorable cases, it is possible to interview experts in the field of interest to explicit the meaning of the reported uncertainties.

Once the nature of the available data has been clarified, one has to build a probability distribution from this sparse information (e.g. preferred value and standard uncertainty). An infinity of pdf's are consistent with such information, and some additional criterion is required to select a unique solution. The Maximum Entropy principle can be used to obtain the least biased solution (Levine and Tribus, 1979). Symmetry principles and central limit theorems are also often invoked in this process. For instance, the product or ratio of a few positive independent random variables takes a log-normal distribution (Limpert et al., 2001; Smith, 2003) which is representative of many physical laws, and which has been extensively used in the context of chemical models (Stewart and Thompson, 1996; Fröhner, 2000; Turányi et al., 2002; Dobrijevic et al., 2003; Vasyunin et al., 2004; Wakelam et al., 2005, 2006). When the only available information is a pair of limit values, symmetry and maximum entropy principles converge towards uniform distributions, which represent indifference about any particular value of the parameter within the imposed limits.

The particular cases of ion-molecule reaction rate constants and branching ratios are considered in the next sections. 


\subsection{Rate constants of ion-molecule reactions}

Reference values for ion-molecule reaction rates $\left(k^{0}\right)$ and their relative uncertainties $(x)$, as reported by Anicich and McEwan (1997), often result from the integration of several experimental values covering a variety of experimental methods, with different uncertainty schemes. A consistent representation of uncertainty by probability distributions should consider that all reported preferred values and uncertainties do not necessarily represent the same state of knowledge. The different experimental techniques involved in ion-molecule rate constant measurements are:

- Flow Tubes: Flowing After Glow, Selected Ion Flow Tube (SIFT), Drift Tube (Adams and Smith, 1988),

- Ion Cyclotron Resonance mass spectrometry (ICR) (Kemper and Bowers, 1988),

- Guided-Ion Beams (Gerlich, 1992).

Flow Tubes and ICR determine rate constants through kinetics measurements whereas Guided-Ion Beams is used to measure reaction cross sections. In the following, we briefly review these methods with a focus on the corresponding uncertainty sources.

Flow Tubes. With the Flow Tubes techniques, ions pass through a flow-tube in a constant flow of helium buffer gas. The neutral reactant is added downstream and the reaction occurs into the flow tube. SIFT and Drift Tube are an improvement of the more general Flowing After Glow techniques. They make it possible to select single ionic species from the ion source and to inject them at low energy into the buffer gas flow. No measurement bias is reported for this method, and the reported uncertainties can be considered as of statistical origin. They are evaluated to about $20 \%$ by Adams and Smith (1976) for SIFT measurements and to about 30\% by Bohme et al. (1969) for Flowing After Glow. 
For studying ion-molecule reaction kinetics at very low temperatures $(\mathrm{T}<200 \mathrm{~K})$, specific Flow Tubes techniques have been developed. The CRESU and the Free Jet Flow Reactor are described in details in Rowe and Parent (1995). Among the different instruments, Rowe and Parent (1995) give a particular attention to the CRESU technique (Cinétiques de Réactions en Ecoulements Supersoniques Uniformes) in which the carrier gas is cooled down by a supersonic expansion. The Free Jet Flow Reactor (Hawley et al., 1990) also uses a supersonic expansion as the cooling system. The experimental uncertainty range is evaluated to about 30\% (Rowe et al., 1984).

ICR. In the case of ICR, the decrease of the parent ion intensity, due to its reaction with the neutral gas, is measured as a function of reactant gas pressure or as a function of time. According to various authors (Huntress and Pinizzoto, 1973; Anicich and Bowers, 1973), the main source of (systematic) uncertainty is the accuracy of the neutral density measurement, which is estimated to about 5-10\% (Anicich and Bowers, 1973; Huntress and Pinizzoto, 1973; Kim et al., 1977). The statistical reproducibility of the rate determination has also been studied by Anicich and Bowers (1973) and is evaluated to a minimum of $20 \%$.

GIB. With the GIB technique, rate constants are calculated through the determination of the reaction cross section, and of the relative velocity of the collisional pair. When all the tests for proper ion collection, transmission and detection are carefully performed, typical statistical uncertainties for the total cross section are expected to be less than 5\% (Teloy and Gerlich, 1974). Nevertheless, a remaining systematic error is estimated to 15-20\% (Teloy and Gerlich, 1974; Ervin and Armentrout, 1985; Nicolas et al., 2002). A difference of $25 \%$ between SIFT and GIB results for the $\mathrm{N}^{+}+\mathrm{CO} \rightarrow \mathrm{CO}^{+}+\mathrm{N}$ reaction has been reported (Gerlich, 1986). Main uncertainty sources involve the measurement of the absolute pressure, the evaluation of the reactant ions path length, the influence of elastic 
collisions and of secondary reactions, and the differences in the collection and detection probabilities for reactant and for product ions (Teloy and Gerlich, 1974). The existence of an unknown bias in the determination of rate constants with the GIB technique means that the reported value $k^{0}$ is not specifically a preferred value. Indeed, any other value within an interval specified using error bars could be accepted.

\subsubsection{Elicitation}

In the reviews of Anicich (1993) and Anicich and McEwan (1997), multiple determinations with GIB, SIFT and ICR techniques are reported for almost all reactions taken into account in the model of Banaszkiewicz et al. (2000). In order to illustrate the elicitation process developed in this paper, we consider two examples of well-studied reactions particularly important for Titan ionosphere chemistry: $\mathrm{N}^{+}+\mathrm{CH}_{4}$ and $\mathrm{N}_{2}^{+}+\mathrm{CH}_{4}$.

[Table 1 about here.]

The references and the preferred values considered by Anicich (1993) are reported in Table 1 . There is a notable dispersion of the values obtained by different methods, but also for different measurements with similar techniques (e.g. 0.94 $0.20,1.1$ and 1.38 with SIFT). In the absence of a documented procedure, we infer that the evaluation of the preferred value may have been performed according to the following criteria:

1. exclusion of the experimental results obtained at low temperature;

2. the preferred value seems to correspond to the mean value between the lowest and the highest reported values;

3. the confidence interval of $15 \%$ reported in both cases is a lower estimation of the interval defined by the lowest and the highest values. 
The reported "preferred" values $\left(k^{0}\right)$ and their associated relative uncertainty cover thus both systematic and statistical uncertainties and would correspond to a "type B" case. Moreover, interpretation of relative uncertainties $(x)$ is not univocal, particularly with regard to their coverage factor. $x$ is generally chosen subjectively to encompass some systematic uncertainties, in the sense that it defines a high confidence interval for $k$. Thus, it includes a subjective security factor, such that there is only a tiny probability for the parameter to be outside of the interval $\left[k^{0}(1-x), k^{0}(1+x)\right]$.

The shape of the distributions has yet to be defined. In the following, we consider two working scenarios: (1) the preferred value defines a maximum of the probability distribution (not necessarily the maximum itself, see below); and (2) there is a total indifference about any particular value within the confidence interval.

(1) $k^{0}$ defines a maximum of the probability distribution. In absence of any other information, and conforming with NIST recommendations (Taylor and Kuyatt, 1994) we should consider that " $k^{0} \pm x \%$ " defines a normal distribution centered on $k^{0}$ with a confidence interval such that

$$
P\left(K \in\left[k^{0}(1-x), k^{0} \times(1+x)\right]\right) \simeq 0.95
$$

This interval is symmetrical about $k^{0}$. We note that this specification of uncertainties for reaction rates is in contrast with the common practice in "neutral" chemistry, where the positivity constraint on the rate constants is acknowledged by using a multiplicative uncertainty factor (see e.g. Atkinson et al., 2004). In this case, a confidence interval is defined by

$$
P(K \in[\operatorname{Med}(k) / F, \operatorname{Med}(k) \times F]) \simeq 0.95
$$


which preserves the positivity of $k$, independently on the value of $F{ }^{2}$ Note that this interval is asymmetric around the median value $\operatorname{Med}(k)$.

The log-normal pdf

$$
p(k \mid \operatorname{Med}(k), F)=\frac{\sqrt{2 / \pi}}{k \ln F} \exp \left(-2\left(\frac{\ln (k / \operatorname{Med}(k))}{\ln F}\right)^{2}\right)
$$

is generally considered as appropriate for uncertainty analysis of chemical reactions (Stewart and Thompson, 1996; Fröhner, 2000; Turányi et al., 2002; Dobrijevic et al., 2003; Vasyunin et al., 2004; Wakelam et al., 2005, 2006) although nothing about this is explicitly stated by the experts defining the reference values and uncertainties (Stewart and Thompson, 1996; Atkinson et al., 2004). This choice is often justified on statistical grounds from the positivity of the rate constants (violated by the normal distribution) and from the central limit theorem for multiplicative errors (formulae relating rate constants to sources of uncertainty involve mainly multiplications and divisions) (Smith and Futrell, 1974; Smith, 1992; Fröhner, 2000; Limpert et al., 2001).

In order to use a log-normal pdf, the information $\left\{k^{0}, x \%\right\}$ has to be recast in the form $\{\operatorname{Med}(k), F\}$. However, it is not possible to match simultaneously a location parameter (mean or median) and the $95 \%$ confidence interval limits. In the present case, it is reasonable to assume that the reference value is more carefully evaluated than the confidence interval and has to be preserved in the transformation. Assigning $k^{0}$ to the median value of the log-normal is generally chosen for the sake of convenience (Stewart and Thompson, 1996). Considering the properties of the log-normal distribution, this enables to separate both parameters, i.e. changing the value of $F$ would not affect the value of the media $\operatorname{Med}(k)=k^{0}$, whereas it would affect the mean value $\left(\operatorname{Mean}(k)=k^{0} \exp \left(\ln ^{2} F / 8\right)\right)$. We

\footnotetext{
${ }^{2}$ The definition of $F$ varies from author to author (Turányi et al., 2002; Dobrijevic et al., 2003; Atkinson et al., 2004) with $\ln F$ representing from $1 \sigma$ to $3 \sigma$ intervals. In this work, we follow the explicit recommendation by Atkinson et al. (2004) that $\left[K^{0} / F, K^{0} F\right]$ represents a 95 percent confidence interval, i.e. $\ln F$ represents a $2 \sigma$ error bar on $\ln K$.
} 
checked that those two options do not lead to significant differences in the uncertainty propagation, and retained the usual assignment of $k^{0}$ to the median. Matching the lower and upper limits of the $95 \%$ interval, leads to two possible values for $F$, namely $F=1 /(1-x)$ and $F=1+x$. In order to guarantee the coverage of the interval, we choose the larger of both values, i.e. $F=1 /(1-x)$. It is to be noted that this might contribute somewhat to an over-weighting of large $k$ values. Preliminary tests showed that for the values of $x$ of interest, rarely above 0.5 , this effect is not qualitatively remarkable.

A foreseeable inconvenience of the log-normal pdf is the absence of an upper limit. Some authors truncate the log-normal distribution within a given confidence interval (Zádor et al., 2005b). For ion molecule reactions, excepted for charge transfer reactions, an upper limit would indeed be provided by the Langevin rate (Armentrout, 2003).

(2) total indifference about a specific value. Another approach is to consider only limit values $\left\{k_{\min }, k_{\max }\right\}$ and to use a distribution reflecting the absence of a preferred value (all values within the interval are considered equally plausible). Considering that for large uncertainties such an interval is expected to cover a few orders of magnitude, we furthermore require that the distribution is uniform for the logarithm of the parameter, ensuring that the distribution is not biased towards large values of the parameter. This is verified by the log-uniform distribution

$$
p\left(k \mid k_{\min }, k_{\max }\right)=\frac{1}{k \ln \left(k_{\max } / k_{\min }\right)}
$$

If one considers, as stated above, that "security factors" are incorporated in the value chosen for $x$, the limits are defined by $k_{\min }=k^{0} \times(1-x)$ and $k_{\max }=k^{0} \times(1+x)$.

As an illustration, we display on Figs. 1 and 2 representative examples for a major $\left(\mathrm{N}_{2}^{+}+\mathrm{CH}_{4} \rightarrow \mathrm{CH}_{2}^{+}+\mathrm{NH}_{2}\right)$ and a minor $\left(\mathrm{H}^{+}+\mathrm{H}_{2} \rightarrow \mathrm{H}_{2}^{+}+\mathrm{H}\right)$ reaction. In the first case, we have a typical reaction with a low uncertainty factor $(x=0.2)$. We observe that the 
range covered by our elicitation of a log-uniform distribution is somewhat more contracted than for the log-normal, and that the shapes of both distributions are quite different. In the case of the second reaction, only an upper value for the reaction rate is known. A lower limit was defined as the sensibility threshold of the experimental technique. When the uncertainty factor is large, as in this case, both distributions become quite similar in shape, if not in range.

[Figure 1 about here.]

[Figure 2 about here.]

\subsection{Uncertainties on the branching ratios}

\subsubsection{Experimental considerations}

Uncertainties on branching ratios are not reported by Anicich (1993) or Anicich and McEwan (1997). In a paper by McEwan et al. (1998), they are estimated to 5\%. In order to evaluate more generally these uncertainties, we compared the values reported by different experts (and for different experimental techniques) for the same reactions as in Section 2.2.1.

Four pathways have been reported for the reaction $\mathrm{N}^{+}+\mathrm{CH}_{4}$ :

$$
\begin{aligned}
\mathrm{N}^{+}+\mathrm{CH}_{4} & \rightarrow \mathrm{CH}_{3}^{+}+\mathrm{NH}(\text { and } / \text { or } \mathrm{N}+\mathrm{H})\left(b_{1}\right) \\
& \rightarrow \mathrm{CH}_{4}^{+}+\mathrm{N}\left(b_{2}\right) \\
& \rightarrow \mathrm{H}_{2} \mathrm{CN}^{+}+\mathrm{H}_{2}\left(b_{3}\right) \\
& \rightarrow \mathrm{HCN}^{+}+\mathrm{NH}\left(b_{4}\right)
\end{aligned}
$$


and three pathways for the reaction $\mathrm{N}_{2}^{+}+\mathrm{CH}_{4}$ :

$$
\begin{aligned}
\mathrm{N}_{2}^{+}+\mathrm{CH}_{4} & \rightarrow \mathrm{CH}_{2}^{+}+\mathrm{N}+\mathrm{H}_{2}\left(b_{1}\right) \\
& \rightarrow \mathrm{CH}_{3}^{+}+\mathrm{N}+\mathrm{H}\left(b_{2}\right) \\
& \rightarrow \mathrm{N}_{2} \mathrm{H}^{+}+\mathrm{CH}_{3}\left(b_{3}\right)
\end{aligned}
$$

Values of the branching ratios measured by different groups are reported in Table 2 along with the relative discrepancies between these measurements and with the values reported in the review of Anicich (1993). The various studies on $\mathrm{N}^{+}+\mathrm{CH}_{4}$ are in rather good agreement. Discrepancies vary between $15 \%$ and $36 \%$. On the other hand, even for a wellstudied reaction such as $\mathrm{N}_{2}^{+}+\mathrm{CH}_{4}$, uncertainty on branching ratios can be much larger. The experimental determination of branching ratios can be subject to large errors due to the many perturbations that can blur the experimental results. Internal or kinetic energy of reactant ions are important parameters that can greatly affect branching ratio measurements. For instance, Alcaraz et al. (2004) showed that branching ratios for the reaction $\mathrm{N}^{+}+\mathrm{CH}_{4}$ change a lot when $\mathrm{N}^{+}$reactant ions are in the $1 \mathrm{D}$ metastable state or when they have some kinetic energy due to their formation from the $\mathrm{N}_{2}^{+}$or $\mathrm{N}_{2}^{++}$dissociation. Temperature can also affect reaction branching ratios. In the case of the $\mathrm{N}_{2}^{+}+\mathrm{CH}_{4}$ reaction, Randeniya and Smith (1991) measured at $30 \mathrm{~K}$ branching ratios, which differ by $10 \%$ from the room temperature ones. It can be much more important for very slightly endothermic reactions such as the formation of $\mathrm{C}_{2} \mathrm{H}_{3}^{+}$in the $\mathrm{C}_{2} \mathrm{H}_{2}^{+}+\mathrm{H}_{2}$ reaction (see the discussion in the review paper from Armentrout and Baer, 1996). Another aspect is the possible mass overlaps and, therefore, the use of appropriate methods to decipher the various product ion assignments. For example, Alcaraz et al. (2004) had to use deuterated and ${ }^{15} \mathrm{~N}$ isotopes in their measurements, in order to clearly ascribe reaction products. Last but not least, even for reactions exhibiting apparently small reaction rates, some reaction products may lead 
to secondary reactions, which are not easy to trace out. Experimentalists have therefore often to find a compromise between the precision on their determination of the total reaction rates by increasing the pressure, and the risk to pollute the branching ratios by the presence of secondary reactions.

Moreover in the case of the reaction $\mathrm{N}_{2}^{+}+\mathrm{CH}_{4}$, the ion product $\mathrm{N}_{2} \mathrm{H}^{+}$has only been observed in the studies of McEwan et al. (1998) and Nicolas et al. (2003). Therefore the branching ratios are defined for three pathways in these two studies and for two pathways in the others. As a result, the branching ratios have a different meaning between both cases and cannot be directly compared. This underlines a recurrent difficulty for the treatment of the branching ratios, which vary with the detection of new products.

[Table 2 about here.]

We expect that the uncertainties observed for these well-studied branching ratios is indeed a lower limit for the uncertainty on the branching ratios of less studied reactions. In the absence of additional information, we assigned a common relative uncertainty to all branching ratios reported in the reviews (Anicich, 1993; Anicich and McEwan, 1997). Levels of 25\%, $50 \%$ and $75 \%$ are considered in the numerical applications. Note that it may seem awkward to assign the same relative uncertainty to all branching ratios of a given reaction. One would expect a better accuracy for major products. This issue is addressed in the next section.

In the case of unknown branching ratios for experimentally detected products (for instance for reactions $\mathrm{C}^{+}+\mathrm{HCN}, \mathrm{CH}_{2}^{+}+\mathrm{N}$, or $\mathrm{CN}^{+}+\mathrm{H}_{2}$ ), it is reasonable to assume a uniform distribution of products with a large relative uncertainty. This would correspond to a situation where a very low detection sensitivity requires that all detected products are above a reasonably high density level, and consequently that they occur in approximately 
similar proportions. A 90\% relative uncertainty, which excludes extreme ratios, is used for such reactions.

\subsubsection{Elicitation}

For a reaction with $n$ product pathways, the partial reaction rates are expressed as $k_{i}=$ $k * b_{i}$, where $k$ is the global reaction rate, and $b_{i}$ are branching ratios characterizing the proportion between the different product pathways. The $b_{i}$ 's are positive and normalized $\left(\sum_{i=1}^{n} b_{i}=1\right)$, which means that they are correlated. The Dirichlet distribution represents the fluctuations of quantities independent of each other, under the condition that their sum remains fixed (Evans et al., 2000). As shown in the Appendix, this multivariate distribution can be uniquely parameterized from the estimated branching ratios $\left(\bar{b}_{i}\right)$ and a relative uncertainty $(x)$ :

$$
\left(b_{1}, \ldots, b_{n}\right) \sim \operatorname{Dirichlet}\left(\hat{\gamma} \times\left(\bar{b}_{1}, \ldots, \bar{b}_{n}\right)\right)
$$

where $\hat{\gamma}$ is a precision factor defined by a least squares equation

$$
\hat{\gamma}=\frac{4}{x^{2}}\left(\frac{\sum_{i} \bar{b}_{i}\left(1-\bar{b}_{i}\right)}{\sum_{i} \bar{b}_{i} \sqrt{\bar{b}_{i}\left(1-\bar{b}_{i}\right)}}\right)^{2}-1
$$

An additional constraint

$$
\hat{\gamma} \geq\left\{\min \left(\max \left(\bar{b}_{1}, 1-\bar{b}_{1}\right), \ldots, \max \left(\bar{b}_{n}, 1-\bar{b}_{n}\right)\right)\right\}^{-1}
$$

is used to ensure the unimodality of the Dirichlet distribution. This distribution respects the average values, i.e. $\left\langle b_{i}\right\rangle=\bar{b}_{i}$, but it cannot reproduce a uniform relative uncertainty 
for all channels. The relative uncertainty for channel $i$

$$
\hat{x}_{i}=2 \sqrt{\frac{\left(1 / \bar{b}_{i}-1\right)}{\hat{\gamma}+1}}
$$

has however the desirable property to be inversely related to the abundance of the product. As was underlined earlier, the uniform relative uncertainty $(x)$ which is generally assigned to all branching ratios should be understood as an average uncertainty. The Dirichlet distribution contributes thus to distribute this uncertainty among channels in a more consistent manner.

Another interesting feature of the Dirichlet distribution is that, in the absence of any information on the branching ratios, it is possible to define a uniform distribution over the $(n-1)$ simplex by taking $\hat{\gamma} b_{1}=\ldots=\hat{\gamma} b_{n}=1$ in Eq. 8. A foreseeable use of this property is the introduction in the reaction scheme of still unobserved, but theoretically plausible pathways (for instance on the basis of their calculated exothermicity). Note that we differentiate this case from the case discussed previously of observed but non quantified products $\left(b_{1}=\ldots=b_{n}=1 / n, x=0.9\right)$.

Example. Let us consider the set of the four branching ratios $(0.5,0.05,0.1,0.36)$ relative to the reaction $\mathrm{N}^{+}+\mathrm{CH}_{4}$. For a $25 \%$ relative uncertainty we estimate $\hat{\gamma}=112$ (Eq. 9). The corresponding "optimal" relative uncertainties $\hat{x}_{i}$ are shown in Table 3 . For the same data with $75 \%$ relative uncertainty, the accuracy factor decreases to $\hat{\gamma}=11.6$. In the latter case, we see that high relative uncertainties (up to 250\%) are produced for the minor channels, whereas the accuracy of the major channels is well preserved. Considering that standard errors on branching ratios are rather gross estimates, this is quite acceptable for the present purpose.

[Table 3 about here.] 


\section{Results and discussion}

\subsection{The model}

In a coupled model of Titan's atmosphere and ionosphere, the stationary densities for ions are calculated by solving iteratively (i) the ion equations with current neutral densities; and (ii) the neutral equations with the production and loss terms estimated at step (i) (Banaszkiewicz et al., 2000). In the present paper, we focus on step (i) involving ion-neutral reactions in absence of transport. The production terms of ions are due to ionization of neutral species by either solar photons or magnetospheric and secondary electrons, and to bimolecular and termolecular reactions. Losses are due to recombination and chemical reactions.

Uncertainty sources in such chemical models are numerous and not necessarily very well quantified. We restrict the present study to parameters involved in bimolecular reactions, namely rate constants and branching ratios. The original model of Banaszkiewicz et al. (2000) involves 33 neutral and 57 ionic species, including two pseudo-ions representing heavy hydrocarbons (those $\mathrm{C}_{x} \mathrm{H}_{y}^{+}$with $x \geq 3$ that are not explicitly included in the model) and heavy nitriles (those $\mathrm{C}_{x} \mathrm{H}_{y} \mathrm{~N}_{z}^{+}$with $x \geq 3$ that are not explicitly included in the model). In order to simulate mass spectra in the 1-100 amu mass scale, as measured by the INMS apparatus on Cassini (Waite et al., 2004, 2005), we relaxed the definition of the pseudo-ions in order to explicitly estimate the density of ions with relevant masses (no new reactions are introduced). Therefore 42 additional product-ions, with the same recombination rate as the pseudo-ions, were explicitly accounted for: $\mathrm{C}_{2} \mathrm{H}_{7}^{+}, \mathrm{CHN}^{+}, \mathrm{CH}_{3} \mathrm{~N}^{+}, \mathrm{CH}_{4} \mathrm{~N}^{+}, \mathrm{C}_{3}^{+}, \mathrm{C}_{3} \mathrm{H}_{8}^{+}$, $\mathrm{C}_{3} \mathrm{H}_{9}^{+}, \mathrm{C}_{2} \mathrm{HN}^{+}, \mathrm{C}_{2} \mathrm{H}_{2} \mathrm{~N}^{+}, \mathrm{C}_{2} \mathrm{H}_{3} \mathrm{~N}^{+}, \mathrm{C}_{2} \mathrm{H}_{4} \mathrm{~N}^{+}, \mathrm{C}_{2} \mathrm{H}_{5} \mathrm{~N}^{+}, \mathrm{C}_{4} \mathrm{H}^{+}, \mathrm{C}_{4} \mathrm{H}_{4}^{+}, \mathrm{C}_{4} \mathrm{H}_{6}^{+}, \mathrm{C}_{4} \mathrm{H}_{8}^{+}, \mathrm{C}_{4} \mathrm{H}_{9}^{+}$, $\mathrm{C}_{2} \mathrm{HN}_{2}^{+}, \mathrm{C}_{3} \mathrm{H}_{6} \mathrm{~N}^{+}, \mathrm{C}_{5} \mathrm{H}^{+}, \mathrm{C}_{5} \mathrm{H}_{2}^{+}, \mathrm{C}_{5} \mathrm{H}_{3}^{+}, \mathrm{C}_{5} \mathrm{H}_{4}^{+}, \mathrm{C}_{5} \mathrm{H}_{7}^{+}, \mathrm{C}_{5} \mathrm{H}_{9}^{+}, \mathrm{C}_{4} \mathrm{~N}^{+}, \mathrm{C}_{4} \mathrm{HN}^{+}, \mathrm{C}_{4} \mathrm{H}_{2} \mathrm{~N}^{+}$, $\mathrm{C}_{4} \mathrm{H}_{4} \mathrm{~N}^{+}, \mathrm{C}_{4} \mathrm{H}_{5} \mathrm{~N}^{+}, \mathrm{C}_{4} \mathrm{H}_{6} \mathrm{~N}^{+}, \mathrm{C}_{6} \mathrm{H}_{2}^{+}, \mathrm{C}_{6} \mathrm{H}_{3}^{+}, \mathrm{C}_{4} \mathrm{~N}_{2}^{+}, \mathrm{C}_{4} \mathrm{HN}_{2}^{+}, \mathrm{C}_{5} \mathrm{H}_{2} \mathrm{~N}^{+}, \mathrm{C}_{5} \mathrm{H}_{3} \mathrm{~N}^{+}, \mathrm{C}_{5} \mathrm{H}_{4} \mathrm{~N}^{+}$, $\mathrm{C}_{5} \mathrm{H}_{5} \mathrm{~N}^{+}, \mathrm{C}_{7} \mathrm{H}_{5}^{+}, \mathrm{C}_{5} \mathrm{HN}_{2}^{+}$and $\mathrm{C}_{6} \mathrm{H}_{2} \mathrm{~N}^{+}$. 
Only reactions with rates available in the literature have been retained, on the basis of the comprehensive survey compiled by Anicich and McEwan (1997). The reaction scheme comprises 584 reactions, with 738 kinetic parameters (315 rate constants and 423 branching ratios). The distribution of those reactions with respect to the number of product pathways is the following: (1) 161, (2) 84, (3) 45, (4) 11, (5) 9, (6) 4 and (7) 1. Thus, about 50\% of the 315 global reactions have multiple pathways, which points out the necessity of a consistent treatment of branching ratios uncertainty.

The densities of major ions, calculated for the nominal values of the parameters, are displayed in Fig. 3, for altitudes between 800 and $1400 \mathrm{~km}$ above Titan's surface, and are compared with the density profiles calculated by Banaszkiewicz et al. (2000). Specification of the pseudo-ions reveals two major ions which will be of relevance for construction of simulated mass-spectra: $\mathrm{C}_{5} \mathrm{H}_{7}^{+}$and $\mathrm{C}_{5} \mathrm{H}_{5} \mathrm{~N}^{+}$. Significant concentrations of $\mathrm{HCNH}^{+}, \mathrm{C}_{2} \mathrm{H}_{5}^{+}$, $\mathrm{C}_{3} \mathrm{H}_{5}^{+}, \mathrm{C}_{5} \mathrm{H}_{5}^{+}$and $\mathrm{C}_{4} \mathrm{H}_{3}^{+}$are predicted by this model. This is in good agreement with the significant contributions predicted by Keller et al. (1998): $\mathrm{HCNH}^{+}$for the mass 28 amu, $\mathrm{C}_{3} \mathrm{H}_{5}^{+}$for the mass $41 \mathrm{amu}, \mathrm{C}_{4} \mathrm{H}_{3}^{+}$for the mass $51, \mathrm{C}_{5} \mathrm{H}_{5}^{+}$for the mass $65 \mathrm{amu}, \mathrm{C}_{5} \mathrm{H}_{7}^{+}$for the mass $67 \mathrm{amu}$, and $\mathrm{C}_{5} \mathrm{H}_{5} \mathrm{~N}^{+}$for the mass $79 \mathrm{amu}$.

[Figure 3 about here.]

\subsection{Simulation}

The sampling for uncertainty propagation of the kinetic parameters has been performed by Monte Carlo simulation.

Inputs. Random numbers are generated by standard algorithms from the Ranlib library (Brown and Lovano, 1991). A sample of inputs is generated by a program independent of the chemical simulation code and stored in a file. This program reads the reference reactions database, containing all relevant parameters (stored as preferred values and relative 
uncertainties), and enables to select different elicitation schemes by keywords.

In order to preserve the intrinsic correlation of the Dirichlet distribution, partial reaction rates for a reaction with $n$ pathways are produced following three steps:

1. a global rate $k$ is sampled from a log-uniform or log-normal distribution;

2. the branching ratios are sampled from the Dirichlet distribution (Eq.8), by generating $n$ independent Gamma deviates with shape parameters $\bar{b}_{1} \hat{\gamma}, \ldots, \bar{b}_{n} \hat{\gamma}$ (Gelman et al., 1995);

3. the partial rate constants are products of two random numbers $\left(k_{i}=k b_{i}\right)_{1}^{n}$.

The distributions are parameterized from the preferred values and the uncertainties reported in the review of Anicich and McEwan (1997). If an uncertainty value is not given, the preferred value is considered as being inaccurate, with a relative error of $60 \%$. As uncertainty is not quantified for branching ratios in this review, three uncertainty classes (25, 50 and $75 \%)$ have been tested. For a few reactions, branching ratios are not reported. In such cases the pathways are considered as equiprobable with an uncertainty of $90 \%$.

As an example of input sample, we consider the three pathways of reaction (7). Fig. 4 represents samples for two limit cases, where either the branching ratios or the rate constant have been fixed to their nominal values (green and blue dots respectively). When the branching ratios are fixed, the sample lies on a straight line, whereas it lies in an hyperplane (simplex) when the rate constant is fixed. These are two extreme correlation patterns. When both items are let to fluctuate, the sample is more relaxed (red dots), it's actual shape depending on their respective uncertainties.

[Figure 4 about here.] 
Outputs. Monte Carlo uncertainty propagation needs very few modifications in the chemistry models. The chemistry code is slightly modified in order to implement a loop over the inputs sample and the storage of the outputs sample (ions densities at various altitudes) in a file. Output samples are treated by a series of independent codes to generate statistical summaries (mean, variance, quantiles...), probability density estimates (histograms or kernel estimation) and derived observables, such as mass spectra. The convergence of the outputs has been tested with $10^{3}, 10^{4}$ and $10^{5}$ samples. Cumulative density functions used for this test were satisfyingly converged for $10^{4}$ samples. Such runs need about one hour cpu time on a current tabletop computer.

\subsection{Uncertainty propagation}

\subsubsection{Uncertainty propagation on rate constants}

The usual way to elicit rate constants uncertainty is through log-normal distributions. Nevertheless we pointed out earlier that a better adapted distribution to elicit ion-molecule rate constants is the log-uniform distribution, mainly because systematic errors are involved in most of the experimental measurements, and also because preferred values and uncertainties issued from a reviewing process pertain to a "type B" uncertainty. One of the main goals of this work is to evaluate the sensitivity of the calculated ion densities to the choice of the input distribution. Uncertainty propagations were performed for log-normal and log-uniform distributions. Examples corresponding to the ions $\mathrm{C}_{3} \mathrm{H}_{5}^{+}$and $\mathrm{N}_{2}^{+}$at 1200 $\mathrm{km}$ are given in Fig. 5. These ions have been chosen for their different position in the reaction scheme:

- $\mathrm{N}_{2}^{+}$is a primary species, directly produced by electron impact and photo ionisation, and essentially consumed by one major reaction, $\mathrm{N}_{2}^{+}+\mathrm{CH}_{4}$;

- $\mathrm{C}_{3} \mathrm{H}_{5}^{+}$is a late product in the reaction scheme, essentially coming from $\mathrm{C}_{2} \mathrm{H}_{5}^{+}+\mathrm{C}_{2} \mathrm{H}_{4}$ 
(Nagy and Cravens, 1998), with $\mathrm{C}_{2} \mathrm{H}_{5}^{+}$itself resulting from two successive reactions.

The shape of the outputs distributions can be strongly dependent on the choice of inputs distribution. With log-normal inputs, the outputs are likewise systematically log-normally distributed. With log-uniform inputs, the shape of the outputs distribution depends on the ion. At $1200 \mathrm{~km}, \mathrm{C}_{3} \mathrm{H}_{5}^{+}$density is well represented by a gaussian distribution whereas $\mathrm{N}_{2}^{+}$density is akin to a log-uniform function. This difference is linked with the number of major reactions in which each ion is involved. Indeed, the central limit theorem forecasts that a sum of independent parameters (with any distribution) converges to a gaussian distribution, and by the same way, that a product of independent parameters converges to a log-normal distribution (Cowan, 1998). Thus $\mathrm{N}_{2}^{+}$being a primary species with one major decay pathway, its pdf is very similar to the log-uniform distribution of the corresponding

reaction rate $k\left(\mathrm{~N}_{2}^{+}+\mathrm{CH}_{4}\right)$. In contrast, $\mathrm{C}_{3} \mathrm{H}_{5}^{+}$being a "late" ion, it's density has a probability density function that is nearly independent of the shape of individual reaction rates distribution.

Apart from this qualitative effect, both elicitation schemes provide essentially the same results for output uncertainty quantification. Moreover there is no computational issue in choosing between log-uniform and log-normal pdf's. As already stated, the log-uniform distribution is more consistent than the log-normal with the epistemic uncertainties affecting ion-molecule rate constants.

[Figure 5 about here.]

\subsubsection{Uncertainty propagation on branching ratios}

To quantify the effect of the uncertainties on the branching ratios, in addition to the uncertainty on the rate constants (modelled from now-on by log-uniform distributions), four cases were compared: no uncertainty, 25\%, 50\% and 75\% relative uncertainty for all 
reactions, with a Dirichlet distribution. The distributions obtained in the case of two major ions $\mathrm{HCNH}^{+}$and $\mathrm{C}_{5} \mathrm{H}_{5}^{+}$are plotted on Fig. 6 and the corresponding relative uncertainties $2 \sigma / \overline{[i o n]}$ are given in Table 4.

[Table 4 about here.]

A progressive broadening of the output distribution with the increasing uncertainty on the branching ratios can be observed for $\left[\mathrm{HCNH}^{+}\right]$. The Dirichlet distribution being asymmetric, an evolution of the pdf shape is also noticeable, giving some more weight to smaller concentrations for this ion. The pattern is different in the case of $\mathrm{C}_{5} \mathrm{H}_{5}^{+}$. The standard deviation on $\left[\mathrm{C}_{5} \mathrm{H}_{5}^{+}\right]$strongly increases between the cases of no uncertainty and $25 \%$ uncertainty, then more progressively until $75 \%$. The reason for this specificity is the presence of a poorly known reaction in the production scheme of $\mathrm{C}_{5} \mathrm{H}_{5}^{+}$. Indeed the reaction $\mathrm{C}_{3} \mathrm{H}_{3}^{+}+\mathrm{C}_{2} \mathrm{H}_{4}$ has two pathways, producing $\mathrm{C}_{5} \mathrm{H}_{5}^{+}$and $\mathrm{C}_{5} \mathrm{H}_{7}^{+}$. The branching ratios of this reaction are unknown and have consequently been assigned a 0.5/0.5 value, with $90 \%$ relative uncertainty (see 2.3.1). A large part of the uncertainty on $\left[\mathrm{C}_{5} \mathrm{H}_{5}^{+}\right]$is consequently due to the large variability of these branching ratios.

[Figure 6 about here.]

In order to appreciate the effect of the branching ratios uncertainties, we computed histograms and sample cumulative density functions from the relative uncertainties of all ions densities, in the absence of branching ratios uncertainty, and in the case of a global $50 \%$ uncertainty, which we consider as the most realistic estimation (see Section 2.3.1). These are reported on Fig. 8 for night-time chemistry at $1000 \mathrm{~km}$ of altitude, on a logarithmic scale. Both distributions are peaked between $10 \%$ and $100 \%$, but whereas uncertainties are all inferior to $100 \%$ when the branching ratios are fixed to their nominal value, about $50 \%$ of the ion densities have a relative uncertainty superior to $100 \%$ in the second case. 
Branching ratios appear thus to be a major source of uncertainty, and the estimated $30 \%$ of uncertainty on ion densities reported by Keller et al. (1992) appears quite optimistic for a large number of species.

We did not find a correlation between densities and relative uncertainties, indicating that the larger uncertainties cannot be assigned uniquely to minor ions. Nevertheless some tendencies related to the ion family can be seen on Figure 7 . Thus the explicitly developed pseudo-ions have all (both hydrocarbons and nitriles) large uncertainties, above $30 \%$. The original nitriles treated in Banaszkiewicz et al. (2000) show a slight tendency of increasing accuracy with the ion density: the most abundant ion $\mathrm{HCNH}^{+}$being also the most accurate one. Finally, the original hydrocarbons treated in Banaszkiewicz et al. (2000) are in general abundant, with a density often superior to $0.01 \mathrm{~cm}^{-3}$, but their uncertainty shows a very large dispersion. It must be pointed out that many relatively abundant hydrocarbons present an uncertainty higher than $50 \%$.

[Figure 7 about here.]

We calculated the uncertainty on the ten most abundant ions (see Table 5) for 1000, 1200 and $1400 \mathrm{~km}$ of altitude and night-time chemistry:

- On the one hand the major component is common to the three altitudes: $\mathrm{HCNH}^{+}$, which is also one of the most accurate compounds in the model, with a relative uncertainty of about $10 \%$. The model is thus relatively well constrained for the most abundant ion in Titan ionosphere.

- On the other hand, numerous heavy species (and in particular some specified expseudo-ions) with poorly known chemistry are among the most abundant ions at 1000 and $1200 \mathrm{~km}$. Therefore their densities present large uncertainties. This highlights the necessity to improve the knowledge about the reactivity of these heavy compounds. 
[Table 5 about here.]

[Figure 8 about here.]

\subsection{Mass spectra}

Mass spectra are calculated with unit mass resolution from the ion densities estimated by the model, using the relative isotopic abundances found in Titan atmosphere: $\mathrm{D} / \mathrm{H}=910^{-5}$ (Mousis et al., 2002), $\mathrm{N}^{14} / \mathrm{N}^{15}=194^{3}$ and $\mathrm{C}^{12} / \mathrm{C}^{13}=95.6$ (Waite et al., 2005).

A mass spectrum was generated at the altitude $1200 \mathrm{~km}$ for night time conditions, in the ram side of Titan with a subram angle of 60 , in order to perform a qualitative comparison to the first INMS Cassini mass spectrum published on the website of the NASA (NASA/JPL/University of Michigan, 2005). As this was not the main purpose of this study, we did not attempt here to simulate further the specific conditions of the T5 flyby during which the INMS spectra were obtained.

Uncertainty bars on the simulated mass spectra presented on Fig. 9 have been calculated by uncertainty propagation with the following conditions: log-uniform distributions for the rate constants and Dirichlet distribution for the branching ratios, with an uncertainty of $50 \%$ for the documented values, and $90 \%$ for the unknown values. Calibration uncertainties have been added on the measured mass spectrum : $20 \%$ at low mass numbers and $50 \%$ at $\mathrm{m} / \mathrm{z}$ of 50 or higher (Cravens et al., 2006).

In spite of the different conditions, the overall adequacy between simulated and measured spectra is quite satisfying for the lower masses (C1, C2, C3 and C4 ions).

Considering the estimated uncertainties, there is a good agreement for a number of mass peaks. However, large discrepancies can be observed, especially in the case of the

\footnotetext{
${ }^{3}$ Taken as the middle of the estimation interval $172<\mathrm{N}^{14} / \mathrm{N}^{15}<215$ (Waite et al., 2005) The fraction of the higher isotope is accordingly bracketed $0.0036<\mathrm{N}^{15} /\left(\mathrm{N}^{14}+\mathrm{N}^{15}\right)<0.0058$. Considering that the number of nitrogen atoms in the nitriles of the model is small (1 or 2), this uncertainty source can be considered as irrelevant to the present work.
} 
C5 ions which are overestimated. This difference will certainly not be corrected by taking additional uncertainty sources into account. On the basis of the rather good agreement for lower masses, we expect that the chemistry model will have to be updated and completed for these compounds, which are presently treated for most of them as terminal species. This will be a preliminary step to any meaningful quantitative comparison and it will require further laboratory experiments. For lower masses, a striking pattern is the systematic under-prediction of densities at masses 18, 30, 42 and 54. The recovery of these densities is also beyond the uncertainties in the chemical parameters. Here again, it is likely that species, or even processes such as fragmentation of large ions (Cravens et al., 2006), are still lacking in the reaction scheme.

[Figure 9 about here.]

\section{Conclusion}

The results of uncertainty propagation of kinetics parameters on ion densities outputs have been reported for the model developed by Banaszkiewicz et al. (2000) for ion-molecule reactivity in the ionosphere of Titan. In comparison with the initial model, 42 pseudo-ions $\mathrm{C}_{x} \mathrm{H}_{y}^{+}$and $\mathrm{C}_{x} \mathrm{H}_{y} \mathrm{~N}_{z}^{+}$have been explicited in order to simulate mass-spectra in the 1-100 amu mass scale as measured by the INMS instrument of Cassini spacecraft.

Uncertainty propagations were performed by Monte Carlo sampling with probability distributions for the rate constants and branching ratios carefully adapted to the chemical data considered in the model. It was shown that a consistent way to describe the uncertainties on the rate constants for ion-molecule reactions reported in the review of Anicich and McEwan (1997) is through a log-uniform distribution. This choice has a qualitative impact on the probability distributions of the model outputs for primary species. As expected from the central limit theorem, the uncertainty distribution for the densities of 
species that occur after a series of reactions is rather insensitive to the specific choice of distribution for the individual reaction rates.

We propose a practical method to treat consistently uncertainties on branching ratios. To our knowledge, we provide here the first study of uncertainty propagation for such correlated parameters in the field of the modelling of complex chemical systems. In the case of our model of Titan's ionospheric chemistry, including the uncertainties on the branching ratios was shown to have a strong impact on the global uncertainty of the predicted ion densities. This study underlines the necessity of a database of evaluated branching ratio uncertainties. Meanwhile, the proposed method opens also the opportunity to treat reactions with totally unknown branching ratios, for instance on the basis of a list of pathways selected for their exothermicity. This subject will be developed in a forthcoming paper (Carrasco and Pernot, 2006).

As an illustration, we compared a simulated mass spectrum for night-time chemistry at $1200 \mathrm{~km}$ of altitude with an experimental mass spectrum measured by Cassini's INMS, available on the website of the NASA (NASA/JPL/University of Michigan, 2005). The shapes and orders of magnitude are globally in good agreement, which is very encouraging. However the uncertainty bars do not overlap for a number of masses, especially in the C5 field. In this article, the trajectory conditions of the T5 Cassini flyby were not precisely simulated. Nevertheless a good agreement was found for the C1, C2, C3 and C4 ions. The overestimation of the C5 region of the mass spectra will thus certainly not be solved by a better simulation of the physical flyby parameters, nor by an adjustment of chemical parameters within their present uncertainty limits, but only by an improvement of the chemical scheme involving the production and loss of C5 ions, and similarly of other heavy ions. New laboratory measurements of rate constants and branching ratios for these species are a necessity, along with recombination rates, most of which are presently estimated (Keller et al., 1992). 
We propose here the preliminary steps for a more complete assessment of uncertainties in the simulation of Titan ionospheric chemistry. Other uncertainty sources will have to be quantified, such as the influence of considering rate constants values determined at $300 \mathrm{~K}$ (instead of $150 \mathrm{~K}$ in the ionosphere of Titan). Another source of expected major importance lies in the uncertainties on the simulated densities of neutral species (Hebrard et al., 2005). The list comprises also recombination rates, electron impact ionisation and photo-ionisation rates...

Once the different uncertainty sources for the present model will have been identified and quantified, the residual inadequacy between simulated and measured spectra will be decreased by further improvements to the chemical scheme. We plan in the near future to consider the sensitivity of the model predictions to presently ignored processes, such as the reactivity of excited states (in particular $\mathrm{N}^{+}\left({ }^{1} D\right)$ (Nicolas et al., 2002)), or the reactivity of doubly charged ions $\mathrm{N}_{2}^{++}$, predicted recently to be present in Titan's ionosphere (Lilensten et al., 2005).

Although the complexity of Titan's ionospheric chemistry precludes any hope of establishing a fully detailed chemistry model, and considering that the INMS instrument will continue to produce invaluable data for many years, we foresee that considerable efforts, including new laboratory experiments, will be put into achieving a complete description of the processes involving ions with masses up to $100 \mathrm{amu}$.

More generally, we feel that the tools we developed in this study, and notably for the treatment of uncertain or unknown branching ratios, will be very helpful to modelers of complex chemical systems. 


\section{Acknowledgements}

We gratefully thank EuroPlaNet for a grant to M.B. which enabled to practically initiate the present work. Part of M.B.'s work was also supported from the Polish State Committee for Scientific Research grant 5 T12E 027 25. We acknowledge the support received from CNRS through a one year postdoctoral position for N.C.

\section{Appendix}

\section{The Dirichlet distribution}

Although it has been only parsimoniously used in chemistry, the Dirichlet distribution is well known to represent the fluctuations of quantities independent of each other, under the condition that their sum remains fixed. In environmental modeling, it has been used to represent uncertainty in chemical composition (mole fractions) (Isukapalli, 1999; Isukapalli and Georgopoulos, 2001), or the partitioning of chemicals between different physical phases (Bates et al., 2003). Justifications for using this distribution can be, as above, its occurrence through ratios of Gamma or $\chi^{2}$ distributions (Isukapalli, 1999; Isukapalli and Georgopoulos, 2001). It has recently been also derived with a random theory of dilution (Vlad et al., 2002), justifying its use for describing the distribution of chemicals after an infinite number of dilutions (geochemistry, nucleotide statistics...).

\section{Properties}

The Dirichlet distribution for a set of $n$ numbers $\left\{b_{i}\right\}_{i=1}^{n}$ summing to 1 , with parameters $\left\{\gamma_{i}\right\}_{i=1}^{n}$,

$$
\left(b_{1}, \ldots, b_{n}\right) \sim \operatorname{Dirichlet}\left(\gamma_{1}, \ldots, \gamma_{n}\right)
$$


has for probability density function

$$
p\left(\left\{b_{i}\right\}_{i=1}^{n} \mid\left\{\gamma_{i}\right\}_{i=1}^{n}\right)=\frac{\Gamma(\gamma)}{\prod_{i=1}^{n} \Gamma\left(\gamma_{i}\right)} \prod_{i=1}^{n} b_{i}^{\gamma_{i}-1}
$$

where $\gamma=\sum_{i=1}^{n} \gamma_{i}$. The mean values, variances and covariances are

$$
\begin{aligned}
\mathrm{E}\left(b_{i}\right) & =\bar{b}_{i}=\frac{\gamma_{i}}{\gamma} \\
\operatorname{Var}\left(b_{i}\right) & =\bar{b}_{i}\left(1-\bar{b}_{i}\right) /(\gamma+1) \\
\operatorname{Cov}\left(b_{i}, b_{j}\right) & =-\bar{b}_{i} \bar{b}_{j} /(\gamma+1)(i \neq j)
\end{aligned}
$$

It can be seen that the Dirichlet distribution can only represent negative covariances which are the direct consequence of the normalization constraint. The marginals of the Dirichlet are Beta distributions

$$
b_{i} \sim \operatorname{Beta}\left(\gamma_{i}, \gamma-\gamma_{i}\right)
$$

\section{Elicitation}

One way to estimate the parameters of the Dirichlet distribution is to select those that provide a good match between the marginal mean values and variances and the target data, i.e. $\left(\bar{b}_{i}, \sigma_{i}\right)_{i=1}^{n}$. This results in the following set of equations, for all $i=1, \ldots, n$ :

$$
\begin{aligned}
\mathrm{E}\left(b_{i}\right) & =\frac{\gamma_{i}}{\gamma}=\bar{b}_{i} \\
\operatorname{var}\left(b_{i}\right) & =\gamma_{i}\left(\gamma-\gamma_{i}\right) /\left(\gamma^{2}(\gamma+1)\right) \\
& =\bar{b}_{i}\left(1-\bar{b}_{i}\right) /(\gamma+1) \\
& =\sigma_{i}^{2}
\end{aligned}
$$


The constraint on the mean is directly satisfied by taking $\gamma_{i}=\bar{b}_{i} \gamma$, which leaves $\gamma$ as the only parameter to be identified from the $n$ marginal variances

$$
\gamma=\frac{\bar{b}_{i}\left(1-\bar{b}_{i}\right)}{\sigma_{i}^{2}}-1, \text { for } i=1, \ldots, n
$$

In general, $\gamma$ cannot satisfy to this set of equations, which underlines that the Dirichlet distribution is too rigid to represent any set of experimental uncertainties (Aitchison, 1986). We propose here that a satisfactory solution can nevertheless be obtained by a least-squares procedure and we define the optimal $\gamma$ value as

$$
\begin{aligned}
\hat{\gamma} & =\operatorname{argmin}_{\gamma} \sum_{i}\left(\sigma_{i}-\left(\frac{\bar{b}_{i}\left(1-\bar{b}_{i}\right)}{\gamma+1}\right)^{1 / 2}\right)^{2} \\
& =\left(\frac{\sum_{i} \bar{b}_{i}\left(1-\bar{b}_{i}\right)}{\sum_{i} \sigma_{i} \sqrt{\bar{b}_{i}\left(1-\bar{b}_{i}\right)}}\right)^{2}-1
\end{aligned}
$$

By taking $\sigma_{i}=x \bar{b}_{i} / 2$, one obtains an equation relating $\hat{\gamma}$ to the relative uncertainty $x$ (see Eq. 9). For large uncertainties, $\hat{\gamma}$ can become very small $(\hat{\gamma} \ll 1)$, which is in agreement with the fact that the Dirichlet distribution becomes non-informative when all it's parameters become vanishingly small (Gelman et al., 1995). However, in such conditions, the Dirichlet and its Beta marginal distributions might become multimodal, with a concentration of probability mass at the borders/corners of the $(n-1)$-simplex. This behavior is not appropriate here, and we avoid it by defining a lower limit for $\hat{\gamma}$. The Beta distribution being bimodal when both it's parameters are smaller than 1, we require that $\hat{\gamma} \bar{b}_{i} \geq 1$ or $\hat{\gamma}\left(1-\bar{b}_{i}\right) \geq 1$ for all $i$. The lower limit is thus

$$
\gamma_{\min }=\left\{\min \left(\max \left(\bar{b}_{1}, 1-\bar{b}_{1}\right), \ldots, \max \left(\bar{b}_{n}, 1-\bar{b}_{n}\right)\right)\right\}^{-1}
$$


and the optimal uncertainty factor is defined simultaneously by Eq. 23 and the condition $\hat{\gamma}>\gamma_{\min }$. The distribution for the branching ratios is accordingly approximated by

$$
\left(b_{1}, \ldots, b_{n}\right) \sim \operatorname{Dirichlet}\left(\hat{\gamma} \times\left(\bar{b}_{1}, \ldots, \bar{b}_{n}\right)\right)
$$

The present parametrization of the Dirichlet distribution relies thus on $n$ position parameters, provided by the reported values of the branching ratios $\left(\bar{b}_{1}, \ldots, \bar{b}_{n}\right)$, and on a single shape parameter $\hat{\gamma}$.

\section{References}

Adams, N., Smith, D., 1976. The selected ion flow tube (SIFT); a technique for studying ion-neutral reactions. International Journal or Mass Spectrometry and Ion Physics, 21(3-4), 349-359.

Adams, N., Smith, D., 1988. Techniques for the study of ion-molecule reactions, volume XX. Wiley Interscience.

Adams, N., Smith, D., Paulson, J., 1980. An experimental survey of the reactions of $\mathrm{NH}_{n}{ }^{+}$ ions $(n=0$ to 4$)$ with several diatomic and polyatomic molecules at $300 \mathrm{~K}$. The Journal of Chemical Physics, 72(1), 288-297.

Aitchison, J., 1986. The Statistical Annalysis of Compositional Data. Monographs on Statistics and Applied Probability. Chapman and Hall, London.

Alcaraz, C., Nicolas, C., Thissen, R., Zabka, J., Dutuit, O., 2004. ${ }^{15} \mathrm{~N}^{+}+\mathrm{CD}_{4}$ and $\mathrm{O}^{+}$ $+{ }^{13} \mathrm{CO}_{2}$ state-selected ion-molecule reactions relevant to the chemistry of planetary ionospheres. J. Phys. Chem. A, 108(45), 9998-10009. 
Anicich, V., 1993. Evaluated bimolecular ion-molecule gas phase kinetics of positive ions for use in modelling planetary atmospheres, cometary comae and interstellar clouds. Journal of Physical and Chemical Reference Data, 22(6), 1469-1569.

Anicich, V., 2003. An index of the literature for bimolecular gas phase cation-molecule reaction kinetics. JPL Publication 03-19, pages 1-1194.

Anicich, V., Bowers, M., 1973. Absolute ion-molecule rate constats from DRIFT cell ion cyclotron resonance spectroscopy. International Journal of Mass Spectrometry and Ion Physics, 11, 329-344.

Anicich, V., Huntress, W., Futrell, J., 1977. Ion Cyclotron Resonance studies of some reactions of $\mathrm{N}^{+}$ions. Chemical Physics Letters, 47, 488-489.

Anicich, V., McEwan, M., 1997. Ion-molecule chemistry in Titan's ionosphere. Planetary and Space Science, 45(8), 897-921.

Anicich, V., P.Wilson, McEwan, M., 2004. A SIFT ion-molecule study of some reactions in Titan's atmosphere. Reactions of $\mathrm{N}^{+}, \mathrm{N}_{2}{ }^{+}$and $\mathrm{HCN}^{+}$with $\mathrm{CH}_{4}, \mathrm{C}_{2} \mathrm{H}_{2}$ and $\mathrm{C}_{2} \mathrm{H}_{4}$. Journal of American Society for Mass Spectrometry, 15, 1148-1155.

Armentrout, P., 2003. The Encyclopedia of Mass Spectrometry, volume 1 - Theory and Ion Chemistry. Elsevier.

Armentrout, P., Baer, T., 1996. Gas-phase ion dynamics and chemistry. J. Phys. Chem., 100, 12866-12877.

Atkinson, R., Baulch, D., Cox, R., Crowley, J., Hampson, R., Hynes, R., Jenkin, M., Rossi, M., Troe, J., 2004. Evaluated kinetic and photochemical data for atmospheric chemistry: Volume $\mathrm{i}$ - gas phase reactions of $\mathrm{O}_{x}, \mathrm{HO}_{x}, \mathrm{NO}_{x}$ and $\mathrm{SO}_{x}$ species. Atmos. Chem. Phys., 4, 1461-1738. 
Banaszkiewicz, M., Lara, L., Rodrigo, R., Lopez-Moreno, J., Molina-Cuberos, G., 2000. A coupled model of Titan's atmosphere and ionosphere. Icarus, 147, 386-404.

Bates, S., Cullen, A., Raftery, A., 2003. Bayesian uncertainty assessment in multicompartment deterministic simulation models for environmental risk assessment. Environmetrics, $14,355-371$.

Bird, M., Dutta-Roy, R., Asmar, S., Rebold, T., 1997. Detection of Titan's ionosphere from Voyager 1 radio occultation observations. Icarus, 130, 426-436.

Bohme, D., Dunkin, D., Fehsenfeld, F., Ferguson, E., 1969. Flowing afterglow studies of ion-molecule association reactions. The Journal of Chemical Physics, 51(3), 863-872.

Broadfoot, A., Sandel, B., Shemansky, D., Holberg, J., Smith, G., Strobel, D., McConnell, J., Kumar, S., Hunten, D., Atreya, S., Donahue, T., Moos, H., Bertaux, J., Blamont, J., Pomphrey, R., Linick, S., 1981. Extreme ultraviolet observations from Voyager 1 encounter with Saturn. Science, 212, 206-211.

Brown, B., Lovano, J., 1991. Ranlib: library of fortran routines for random number generation. Department of Biomathematics, M.D. Anderson Cancer Center, University of Texas, Houston.

Carrasco, N., Pernot, P., 2006. Modeling of branching ratio uncertainty in chemical networks by dirichlet distributions. PCCP. in preparation.

Cowan, G., 1998. Statistical data analysis. Oxford Science Publications.

Cravens, T., Robertson, I., Jr, J. W., Kasprzak, W., Keller, C., Ledvina, S., Niemann, H., Luhmann, J., McNutt, R., Ip, W., Haye, V. D. L., Mueller-Wodarg, I., Wahlung, J., Anicich, V., Vuitton, V., 2006. The composition of Titan's ionosphere. Geophysical Research Letters, submitted. 
d'Agostini, G., 2003. Bayesian Reasoning in Data Analysis: A Critical Introduction. World Scientific Pub. Co. Inc.

Dheandhanoo, S., Johnsen, R., Biondi, M., 1984. Measured ion-molecule reaction rates for modelling Titan's atmosphere. Planetary and Space Science, 32(10), 1301-1305.

Dobrijevic, M., Ollivier, J. L., Billebaud, F., Brillet, J., Parisot, J., 2003. Effect of chemical kinetic uncertainties on photochemical modeling results: Application to Saturn's atmosphere. A \& A, 398, 335-344.

Dobrijevic, M., Parisot, J., 1998. Effect of chemical kinetic uncertainties on hydrocarbon production in the stratosphere of neptune. Planetary and Space Science, 46, 491-505.

Ervin, K., Armentrout, P., 1985. Translational energy dependence of $\mathrm{Ar}^{+}+\mathrm{XY}->\mathrm{ArX}^{+}+\mathrm{Y}$ $\left(\mathrm{XY}=\mathrm{H}_{2}, \mathrm{D}_{2}, \mathrm{HD}\right)$ from thermal to $30 \mathrm{eV}$ c.m. Journal of Chemical Physics, 83, 166-189.

Evans, M., Hastings, N., Peacock, B., 2000. Statistical Distributions. Wiley-Interscience, 3rd edition.

Fox, J., Yelle, R., 1997. Hydrocarbon ions in the ionosphere of Titan. Geophysical Research Letters, 24, 2179.

Fröhner, F., 2000. Evaluation and Analysis of Nuclear Resonance Data. JEFF Report 18, Nuclear Energy Agency and Organization for Economic Co-operation and Development.

Garthwaite, P., Kadane, J., O'Hagan, A., 2005. Statistical methods for eliciting probability distributions. Journal of the American Statistical Association, 100, 680-701.

Gelman, A., Carlin, J., Stern, H., Rubin, D., 1995. Bayesian Data Analysis. Chapman \& Hall, London. 
Gerlich, D., 1986. Electronic and atomic collisions, chapter Low energy ion reactions measured with guided beams, page 541. North Holland.

Gerlich, D., 1992. Inhomogeneous RF Fields: A Versatile Tool for the Study of Processes with Slow Ions.

Hanel, R., Conrath, B., Flasar, F., Kunde, V., Maguire, W., Pearl, J., Pirraglia, J., Samuelson, R., Herath, L., Allison, M., Cruikshank, D., Gautier, D., Gierasch, P., Horn, L., Koppany, R., Ponnamperuma, C., 1981. Infrared observations of the Saturnian system from Voyager 1. Science, 212, 192-200.

Hanson, K., Hemez, F. M., 2003. Uncertainty quantification of simulation codes based on experimental data. In Proc. 41st AIAA Aerospace Sciences, Washington DC. AIAA.

Hawley, M., Mazely, T., Randeniya, L., Smith, R., Zeng, X., Smith, M., 1990. A free jet flow reactor for ion/molecule reaction studies at very low energies. International Journal of Mass Spectrometry and Ion Processes, 97, 55-86.

Hebrard, E., Bénilan, Y., Raulin, F., 2005. Sensitivity effects of photochemical parameters uncertainties on hydrocarbon production in the atmosphere of Titan. Adv. Space Res., $36,268-273$.

Helton, J., 2005. Sampling-based methods for uncertainty and sensitivity analysis. In Hanson, K. M., Hemez, F. M., editors, Sensitivity Analysis of Model Output (SAMO 2004), pages 221-229, Los Alamos National Laboratory, Los Alamos.

Helton, J., Davis, F., 2000. Sensitivity Analysis, chapter Samplin-based methods, pages 101-153. Wiley Series in Probability and Statistics. Wiley.

Huntress, W., 1977. Laboratory studies of bimolecular reactions ions in interstellar clouds, 
comets, and in planetary atmospheres of reducing composition. Astrophysical Journal Supplement Series, 33, 495-514.

Huntress, W., Pinizzoto, R., 1973. Product distributions and rate constants for ionmolecule reactions in water, hydrogen sulfide, ammonia, and methane. The Journal of Chemical Physics, 59(9), 4742-4555.

Ip, W., 1990. Titan's upper ionosphere. Astrophysical Journal, 362, 354-363.

Isukapalli, S., 1999. Uncertainty analysis of transport-transformation models. PhD thesis, Graduate School - New Brunswick, Rutgers, The State University of New Jersey.

Isukapalli, S., Georgopoulos, P., 2001. Computational methods for sensitivity analysis and uncertainty analysis for environmental and biological models. Technical Report EPA/600/R-01-068, U.S. Environmental Protection Agency, Research Triangle Park, NC27711.

Jenkinson, D., 2005. The elicitation of probabilities - A review of the statistical literature. BEEP working paper, University of Sheffield.

Keller, C., Anicich, V., Cravens, T., 1998. Model of Titan's ionosphere with detailed hydrocarbon ion chemistry. Planetary and Space Science, 46, 1157.

Keller, C., Cravens, T., Gan, L., 1992. A model of the ionosphere of Titan. Journal of Geophysical Research, 97, 12117.

Kemper, P., Bowers, M., 1988. Techniques for the study of ion-molecule reactions, volume XX. Wiley Interscience.

Kim, J., Anicich, V., Huntress Jr, W., 1977. Product distributions and rate constants for the reactions of $\mathrm{CH}_{3}^{+}, \mathrm{CH}_{4}^{+}, \mathrm{C}_{2} \mathrm{H}_{2}^{+}, \mathrm{C}_{2} \mathrm{H}_{3}^{+}, \mathrm{C}_{2} \mathrm{H}_{4}^{+}, \mathrm{C}_{2} \mathrm{H}_{5}^{+}$, and $\mathrm{C}_{2} \mathrm{H}_{6}^{+}$ions with $\mathrm{CH}_{4}, \mathrm{C}_{2} \mathrm{H}_{2}$, $\mathrm{C}_{2} \mathrm{H}_{4}$ and $\mathrm{C}_{2} \mathrm{H}_{6}$. Journal of Physical Chemistry, 81(19), 1798-1805. 
Levine, R., Tribus, M., 1979. The Maximum Entropy formalism. MIT Press, Cambridge, MA.

Lilensten, J., Witasse, O., Simon, C., Solidi-Lose, H., Dutuit, O., Thissen, R., Alcaraz, C., 2005. Prediction of a $\mathrm{N}_{2}^{++}$layer in the upper atmosphere of Titan. Geophysical Research Letters, 32(3).

Limpert, E., Stahel, W., Abbt, M., 2001. Log-normal distributions across the sciences: keys and clues. Bioscience, 51, 341-352.

McEwan, M., Scott, G., Anicich, V., 1998. Ion-molecule reactions relevant to Titan's ionosphere. International Journal of Mass Spectrometry and Ion Processes, 172, 209219.

Minard, R., 2005. A survey of data and publications relating to Titan atmospheric chemistry studies. http://psarc.geosc.psu.edu/TITAN/TitanChemBiblio.pdf.

Mousis, O., Gautier, D., Cousténis, A., 2002. The D/H ratio in methane in Titan: origin and history. Icarus, 159, 156-165.

Nagy, A., Cravens, T., 1998. Titan's ionosphere: a review. Planet. Space Sci., 46(9/10), $1149-1155$.

NASA/JPL/University of Michigan, 2005. PIA07865: Titan's upper atmosphere: A "factory" of hydrocarbons. INMS spectrum at $1200 \mathrm{~km}$ (http://photojournal.jpl.nasa.gov/catalog/PIA07865).

Nicolas, C., Alcaraz, C., Thissen, R., Zabka, J., Dutuit, O., 2002. Effects of ion excitation on charge transfer reactions of the Mars, Venus and Earth ionospheres. Planetary and Space Science, 50, 877-887. 
Nicolas, C., Torrents, R., Gerlich, D., 2003. Integral and differential cross section measurements at low collision energies for the $\mathrm{N}_{2}{ }^{+}+\mathrm{CH}_{4} / \mathrm{CD}_{4}$ reactions. The Journal of Chemical Physics, 118(6), 2723-2730.

Randeniya, L., Smith, M., 1991. Gas phase reaction rates of $\mathrm{N}_{2}{ }^{+}$with $\mathrm{CH}_{4}, \mathrm{O}_{2}$, and n- $\mathrm{H}_{2}$ at very low temperatures. Journal of Chemical Physics, 94(1), 351-356.

Roboz, A., Nagy, A., 1994. The energetics of Titan's ionosphere. Journal of Geophysical Research, 99, 2087-2093.

Rowe, B., Dupeyrat, G., Marquette, J., Gaucherel, P., 1984. Study of the reactions $\mathrm{N}_{2}{ }^{+}+2 \mathrm{~N}_{2}=\mathrm{N}_{4}{ }^{+}+\mathrm{N}_{2}$ and $\mathrm{O}_{2}{ }^{+}+2 \mathrm{O}_{2}=\mathrm{O}_{4}{ }^{+}+\mathrm{O}_{2}$ from $20 \mathrm{~K}$ to $160 \mathrm{~K}$ by the CRESU technique. Journal of Chemical Physics, 80, 4915-4921.

Rowe, B., Marquette, J., Dupeyrat, G., 1985. Reactions of $\mathrm{He}^{+}$and $\mathrm{N}^{+}$ions with several molecules at 8K. Chemical Physics Letters, 113(4), 403-406.

Rowe, B., Marquette, J., Rebrion, C., 1989. Mass-selected ion-molecule reactions at very low temperatures. the CRESUS apparatus. Journal of the Chemical Society, Faraday Transactions 2, 85(10), 1631-1641.

Rowe, B., Parent, D., 1995. Techniques for the study of reaction kinetics at low temperatures : application to the atmospheric chemistry of Titan. Planetary and Space Science, 43(1), 105-114.

Saltelli, A., Ratto, M., Tarantola, S., Campolongo, F., 2005. Sensitivity analysis for chemical models. Chem. Rev., 105, 2811-2827.

Samuelson, R., Nath, N., Borysow, A., 1997. Gaseous abundances and methane supersaturation in titan's troposphere. Planetary and Space Science, 45, 959-980. 
Smith, D., 2003. A demonstration of the lognormal distribution. Report ANL/NDM-156, Argonne National Laboratory.

Smith, D., Adams, N., Miller, T., 1978. A laboratory study of the reactions of $\mathrm{N}^{+}, \mathrm{N}_{2}{ }^{+}$, $\mathrm{N}_{3}{ }^{+}, \mathrm{O}^{+}, \mathrm{O}_{2}{ }^{+}$, and $\mathrm{NO}^{+}$ions with several molecules at $300 \mathrm{~K}$. The Journal of Chemical Physics, 69(1), 308-318.

Smith, D., Futrell, J., 1974. A new tandem mass spectrometer for the study of ion-molecule reactions. International Journal or Mass Spectrometry and Ion Physics, 14(2), 171-181.

Smith, M., 1992. Ion-molecule reaction dynamics at very low temperatures, volume 82, chapter State-selected and state-to-state ion-molecule reaction dynamics. Part 1- Experiment, pages 183-251. John Wiley.

Stewart, R., Thompson, A., 1996. Kinetic data imprecisions in photochemical rate calculations: means, medians and temperature dependance. J. Geophys. Res., 101, 2093520964.

Taylor, B., Kuyatt, C., 1994. Guidelines for evaluating and expressing the uncertainty of NIST measurement results. Technical Note 1297, National Institute of Standards and Technology, U.S. Government Printing Office, Washington DC.

Teloy, E., Gerlich, D., 1974. Integral cross sections for ion-molecule reactions. I - the guided beam technique. Chemical Physics, 4, 417-427.

Thompson, A., Stewart, R., 1991. Effect of chemical kinetics uncertainties on calculated constituents in a tropospheric photochemical model. Journal of Geophysical Research, 96, 13089-13108.

Tichy, M., Rakshit, A., Lister, D., Twiddy, N., Adams, N., Smith, D., 1979. A study of the 
reactions of the ground and metastable states of $\mathrm{C}^{+}, \mathrm{N}^{+}, \mathrm{S}^{+}$and $\mathrm{N}_{2}^{+}$at $300 \mathrm{~K}$. Journal of Mass Spectrometry and Ion Physics, 29, 231-247.

Toublanc, D., Parisot, J., Brillet, J., Gautier, D., Raulin, F., McKay, C., 1995. Photochemical modeling of Titan's atmosphere. Icarus, 113, 2-26.

Turányi, T., Zalotai, L., Dóbé, S., Bérces, T., 2002. Effect of the uncertainty of kinetic and thermodynamic data on methane flame simulation results. Phys. Chem. Chem. Phys., 4, 2568-2578.

Vasyunin, A., Sobolev, A., Wiebe, D., Semenov, D., 2004. Influence of uncertainties in the rate constants of chemical reactions on astrochemical modeling results. Astronomy Letters, 30(8), 566-576.

Vlad, M., Tsuchiya, M., Oefner, P., Ross, J., 2002. Bayesian analysis with random chemical composition: Renormalization-group approach to Dirichlet distributions and the statistical theory of dilution. Phys. Rev. E, 65, 011112.

Waite, J., Lewis, W., Kasprzak, W., Anicich, V., Block, B., Cravens, T., Fletcher, G., Ip, W.-H., Luhmann, J., Mcnutt, R., Niemann, H., Parejko, J., Richards, J., Thorpe, R., Walter, E., Yelle, R., 2004. The Cassini Ion and Neutral Mass Spectrometer (INMS) Investigation. Space Science Reviews, 114(1), 113-231.

Waite, J., Niemann, H., Yelle, R., Kasprzak, W., Cravens, T., Luhmann, J., McNutt, R., Ip, W.-H., Gell, D., Haye, V. D. L., Muller-Wordag, I., Magee, B., Borggren, N., Ledvina, S., Fletcher, G., Walter, E., Miller, R., Scherer, S., Thorpe, R., Xu, J., Block, B., Arnett, K., 2005. Ion Neutral Mass Spectrometer Results from the First Flyby of Titan. Science, 308(5724), 982-986.

Wakelam, V., Herbst, E., Selsis, F., 2006. The effect of uncertainties on chemical models of dark clouds. A. \& A., In press. 
Wakelam, V., Selsis, F., Herbst, E., Caselli, P., 2005. Estimation and reduction of the uncertainties in chemical models: application to hot core chemistry. A. \& A., 444, 883-891. in press.

Wilson, E., Atreya, S., 2004. Current state of modeling the photochemistry of Titan's mutually dependent atmosphere and ionosphere. Journal of Geophysical Research, 109, $\mathrm{E} 06002$.

Yung, Y., Allen, M., Pinto, J., 1984. Photochemistry of the atmosphere of Titan - comparison between model and observations. Astrophysical Journal Supplement Series, 55, $465-506$.

Zádor, J., Wagner, V., Wirtz, K., Pilling, M., 2005a. Quantitative assessment of uncertainties for a model of ethene oxidation using the European Photoreactor (EUPHORE). Atmospheric Environment, 39, 2805-2817.

Zádor, J., Zsély, I. G., Turányi, T., Ratto, M., Tarantola, S., Saltelli, A., 2005b. Local and global uncertainty analyses for a methane flame model. J. Phys. Chem., 109, 9575-9807. 


\section{List of Figures}

1 Elicitation of the probability density function for the rate constant of the reaction $\mathrm{N}_{2}^{+}+\mathrm{CH}_{4} \rightarrow \mathrm{CH}_{2}^{+}+\mathrm{NH}_{2} \quad\left(b_{1}=0.7\right)$, with preferred value for the global rate $k^{0}=1.510^{-9}$ and relative uncertainty $x=0.2$. Comparison of probability densities for: (upper panel) a log-normal distribution $\left(k^{0}=1.510^{-9}, F=1.25\right)$; (lower panel) a log-uniform distribution $\left(k_{\min }=\right.$ $\left.1.210^{-9}, k_{\max }=1.810^{-9}\right)$. In both cases, the rate constant is multiplied by the (fixed) branching ratio $\left(k_{1}=k b_{1}\right)$. The histograms are built from $10^{5}$ samples. . . . . . . . . . . . . . . . . . .

2 Elicitation of probability density function for the rate constant of the reaction $\mathrm{H}^{+}+\mathrm{H}_{2} \rightarrow \mathrm{H}_{2}^{+}+\mathrm{H}$. Comparison of probability densities for: (upper panel) a log-normal distribution $\left(k^{0}=510^{-13}, F=435\right)$; (lower panel) a loguniform distribution $\left(k_{\min }=1.210^{-15}, k_{\max }=1.010^{-12}\right)$. The histograms are built from $10^{5}$ samples. . . . . . . . . . . . . . . . . . .

3 Ion density profiles with and without specification of pseudo-ions in the model: (thin solid lines) common major ions; (thick solid lines) major former pseudo-ions; (dashed lines) $\mathrm{C}_{\mathrm{x}} \mathrm{H}_{\mathrm{y}} \mathrm{N}_{\mathrm{z}}^{+}$and $\mathrm{C}_{\mathrm{x}} \mathrm{H}_{\mathrm{y}}^{+}$pseudo-ions in the original model. . . . . . . . . . . . . . . . . .

4 Partial rates of reaction 7. The samples have been generated according the following scheme: (green) fixed branching ratios and log-uniform distribution for $k^{0}$; (blue) fixed $k^{0}$ and Dirichlet distribution for the branching ratios; and (red) log-uniform distribution for $k^{0}$ and Dirichlet distribution for the branching ratios. . . . . . . . . . . . . .

$5 \quad \mathrm{C}_{3} \mathrm{H}_{5}^{+}$and $\mathrm{N}_{2}^{+}$density distributions at $1200 \mathrm{~km}$ obtained by uncertainty propagation with log-uniform (thick line) and log-normal (dotted line) rate constant uncertainties. Horizontal boxplots depict the 5/25/50/75/95 quan-

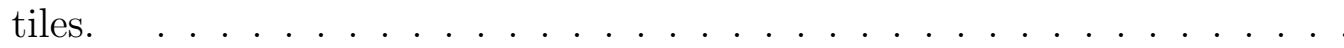

$6 \mathrm{HCNH}^{+}$and $\mathrm{C}_{5} \mathrm{H}_{5}^{+}$density distributions at $1200 \mathrm{~km}$ for night-time chemistry: with no (dashed line) / 25\% (thin line) / 50\% (normal line) / $75 \%$ (thick line) relative uncertainty on the branching ratios. Horizontal boxplots depict the $5 / 25 / 50 / 75 / 95$ quantiles. . . . . . . . . . . . . . . . . . . Relative uncertainties versus ion densities at $1200 \mathrm{~km}$ of altitude by nighttime chemistry. . . . . . . . . . . . . . . .

8 Distribution of the uncertainties for all ions densities. The full line represents the sample cumulative density function. The simulations were performed by night-time chemistry at $1000 \mathrm{~km}$ of altitude for two cases of uncertainty on the branching ratios: (above) no uncertainty ; (below) 50\% relative uncer-

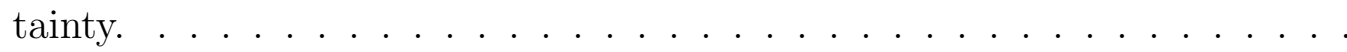

9 Simulated (drop lines) and measured (envelope) mass spectra of Titan ionosphere at $1200 \mathrm{~km}$ of altitude by night time. Box-plots and error bars correspond to confidence intervals of $50 \%$ and $90 \%$ for the calculated mass spectrum. Vertical boxplots depict the $5 / 25 / 50 / 75 / 95$ quantiles. . . . . . . 


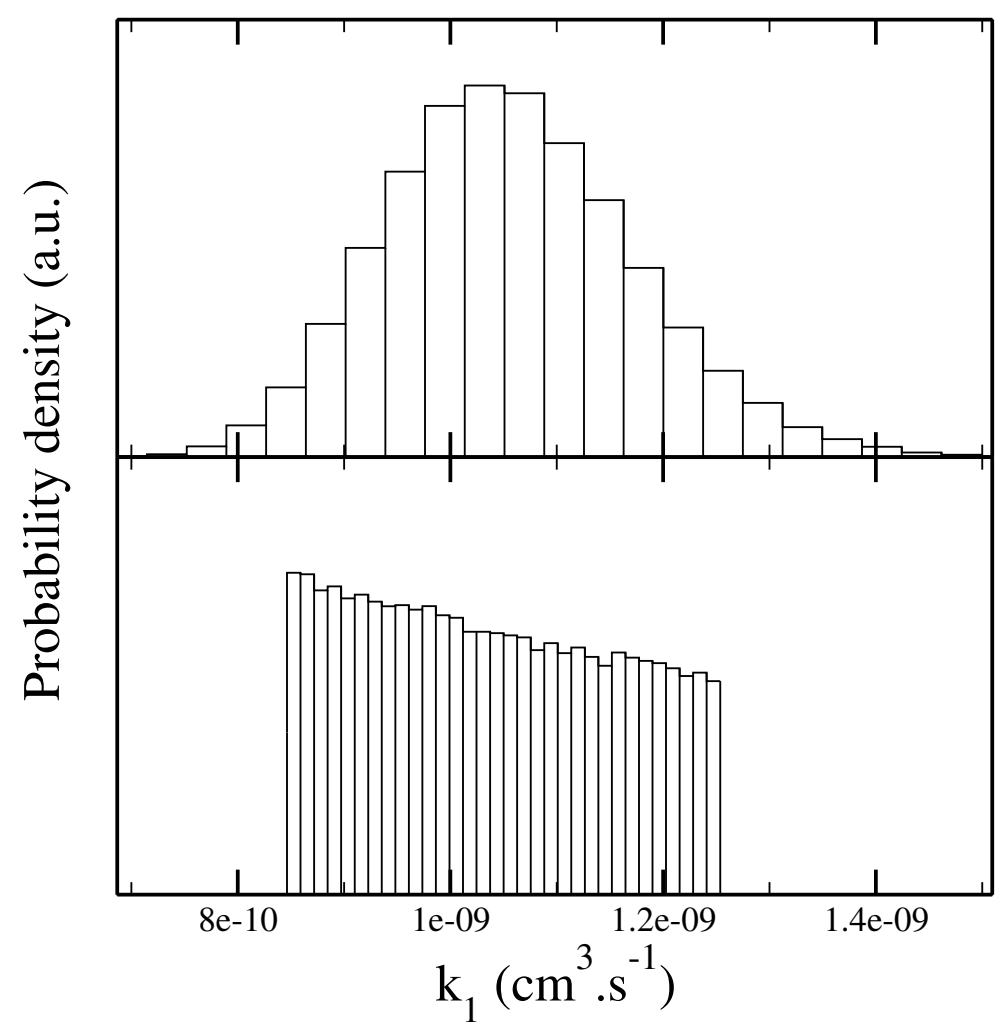

Figure 1: Elicitation of the probability density function for the rate constant of the reaction $\mathrm{N}_{2}^{+}+\mathrm{CH}_{4} \rightarrow \mathrm{CH}_{2}^{+}+\mathrm{NH}_{2}\left(b_{1}=0.7\right)$, with preferred value for the global rate $k^{0}=1.510^{-9}$ and relative uncertainty $x=0.2$. Comparison of probability densities for: (upper panel) a log-normal distribution $\left(k^{0}=1.510^{-9}, F=1.25\right)$; (lower panel) a log-uniform distribution $\left(k_{\min }=1.210^{-9}, k_{\max }=1.810^{-9}\right)$. In both cases, the rate constant is multiplied by the (fixed) branching ratio $\left(k_{1}=k b_{1}\right)$. The histograms are built from $10^{5}$ samples. 


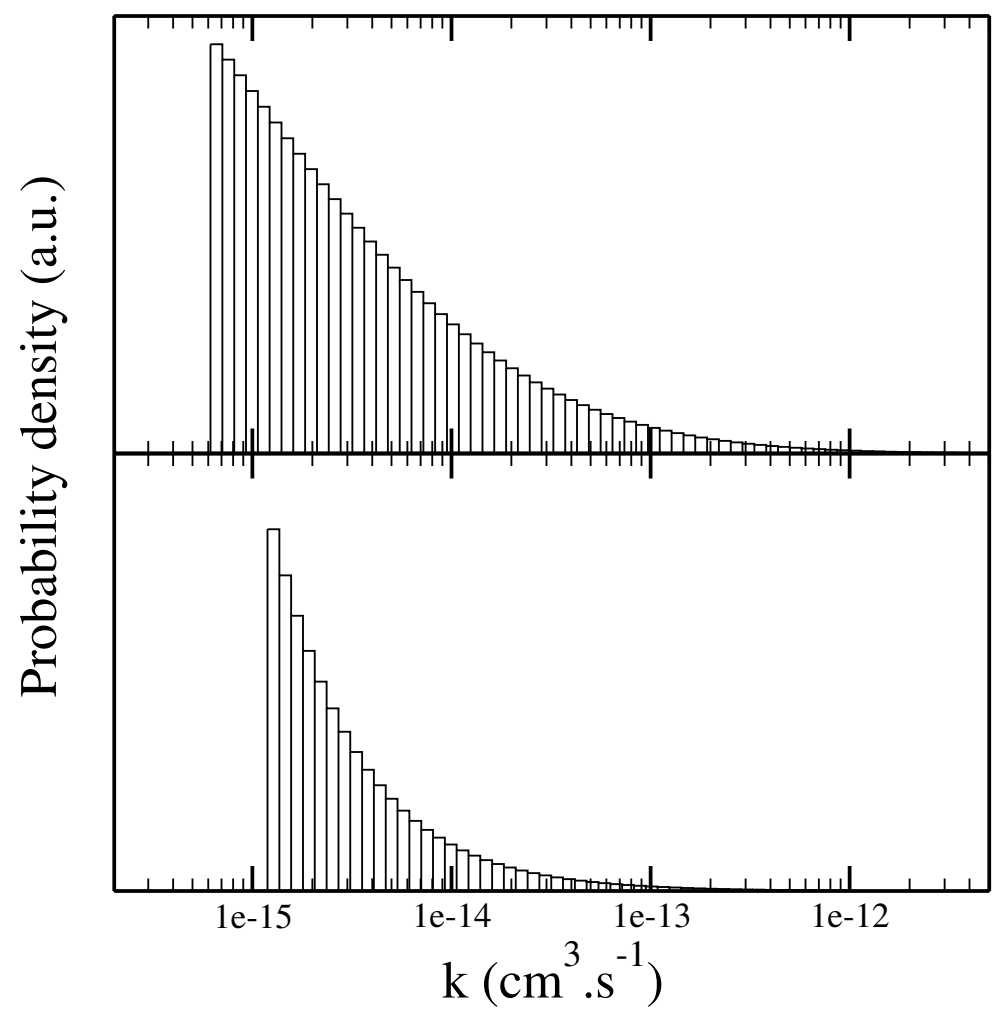

Figure 2: Elicitation of probability density function for the rate constant of the reaction $\mathrm{H}^{+}+\mathrm{H}_{2} \rightarrow \mathrm{H}_{2}^{+}+\mathrm{H}$. Comparison of probability densities for: (upper panel) a log-normal distribution $\left(k^{0}=510^{-13}, F=435\right)$; (lower panel) a log-uniform distribution $\left(k_{\min }=\right.$ $\left.1.210^{-15}, k_{\max }=1.010^{-12}\right)$. The histograms are built from $10^{5}$ samples. 


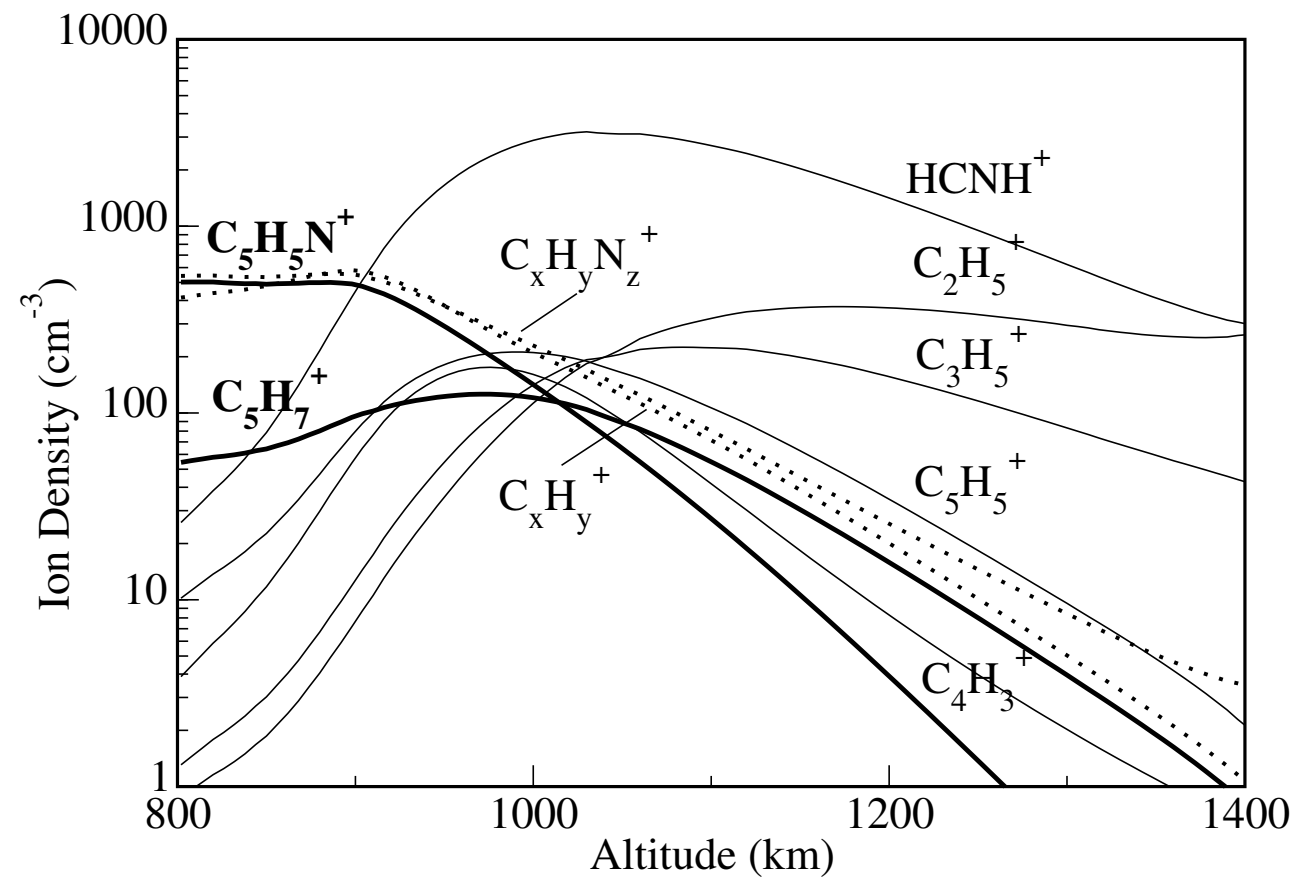

Figure 3: Ion density profiles with and without specification of pseudo-ions in the model: (thin solid lines) common major ions; (thick solid lines) major former pseudo-ions; (dashed lines) $\mathrm{C}_{\mathrm{x}} \mathrm{H}_{\mathrm{y}} \mathrm{N}_{\mathrm{z}}^{+}$and $\mathrm{C}_{\mathrm{x}} \mathrm{H}_{\mathrm{y}}^{+}$pseudo-ions in the original model. 

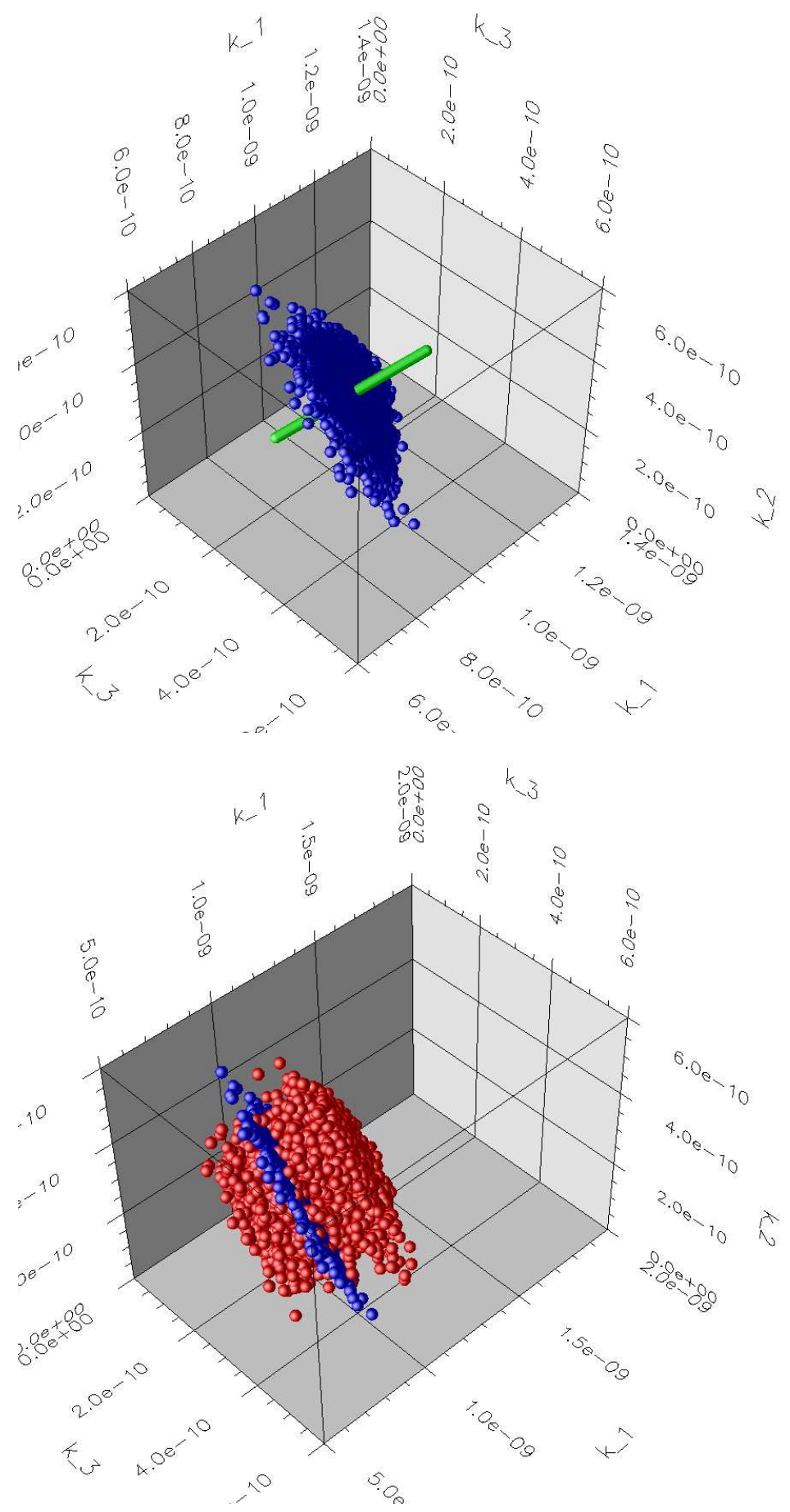

Figure 4: Partial rates of reaction 7 . The samples have been generated according the following scheme: (green) fixed branching ratios and log-uniform distribution for $k^{0}$; (blue) fixed $k^{0}$ and Dirichlet distribution for the branching ratios; and (red) log-uniform distribution for $k^{0}$ and Dirichlet distribution for the branching ratios. 

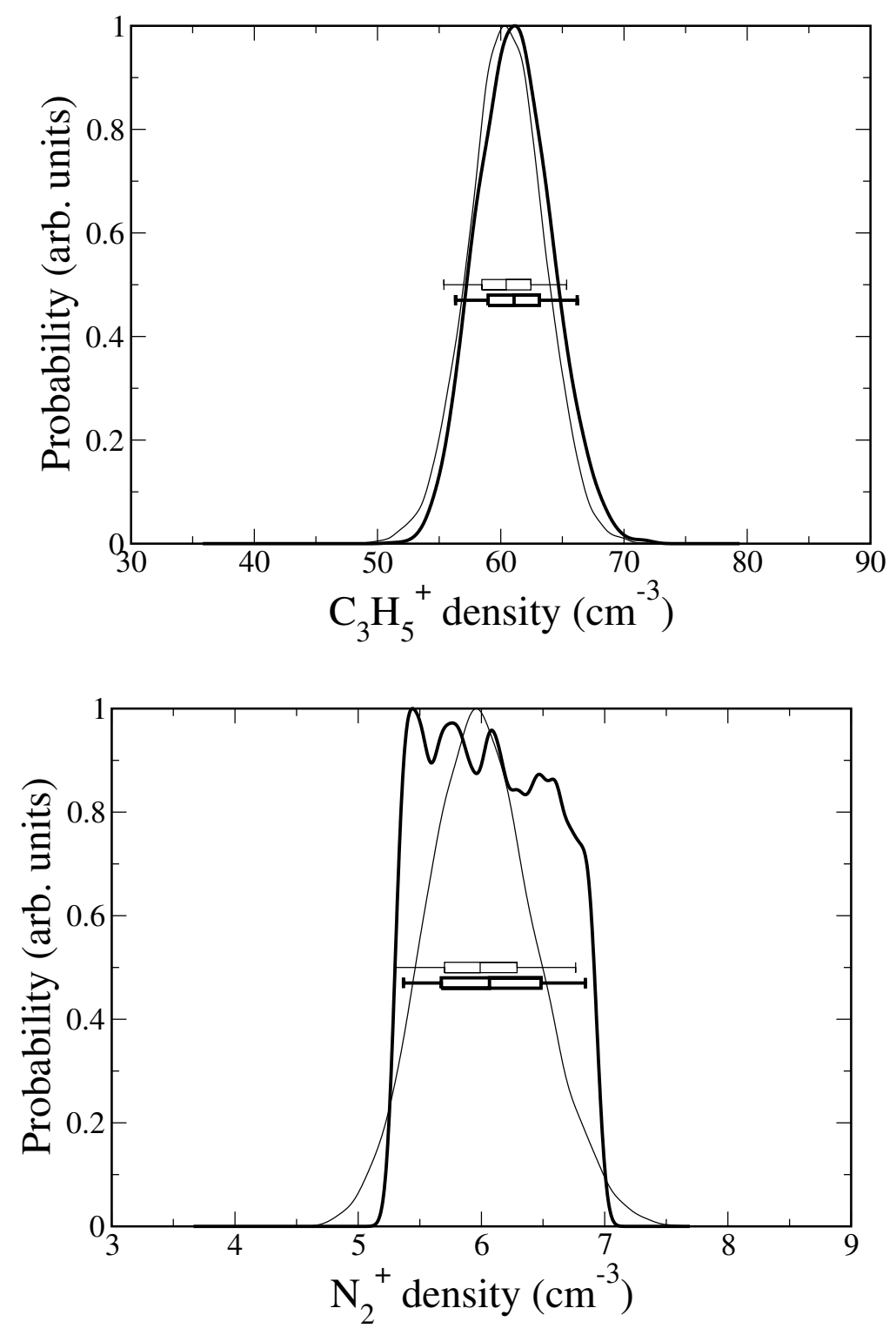

Figure 5: $\mathrm{C}_{3} \mathrm{H}_{5}^{+}$and $\mathrm{N}_{2}^{+}$density distributions at $1200 \mathrm{~km}$ obtained by uncertainty propagation with log-uniform (thick line) and log-normal (dotted line) rate constant uncertainties. Horizontal boxplots depict the 5/25/50/75/95 quantiles. 

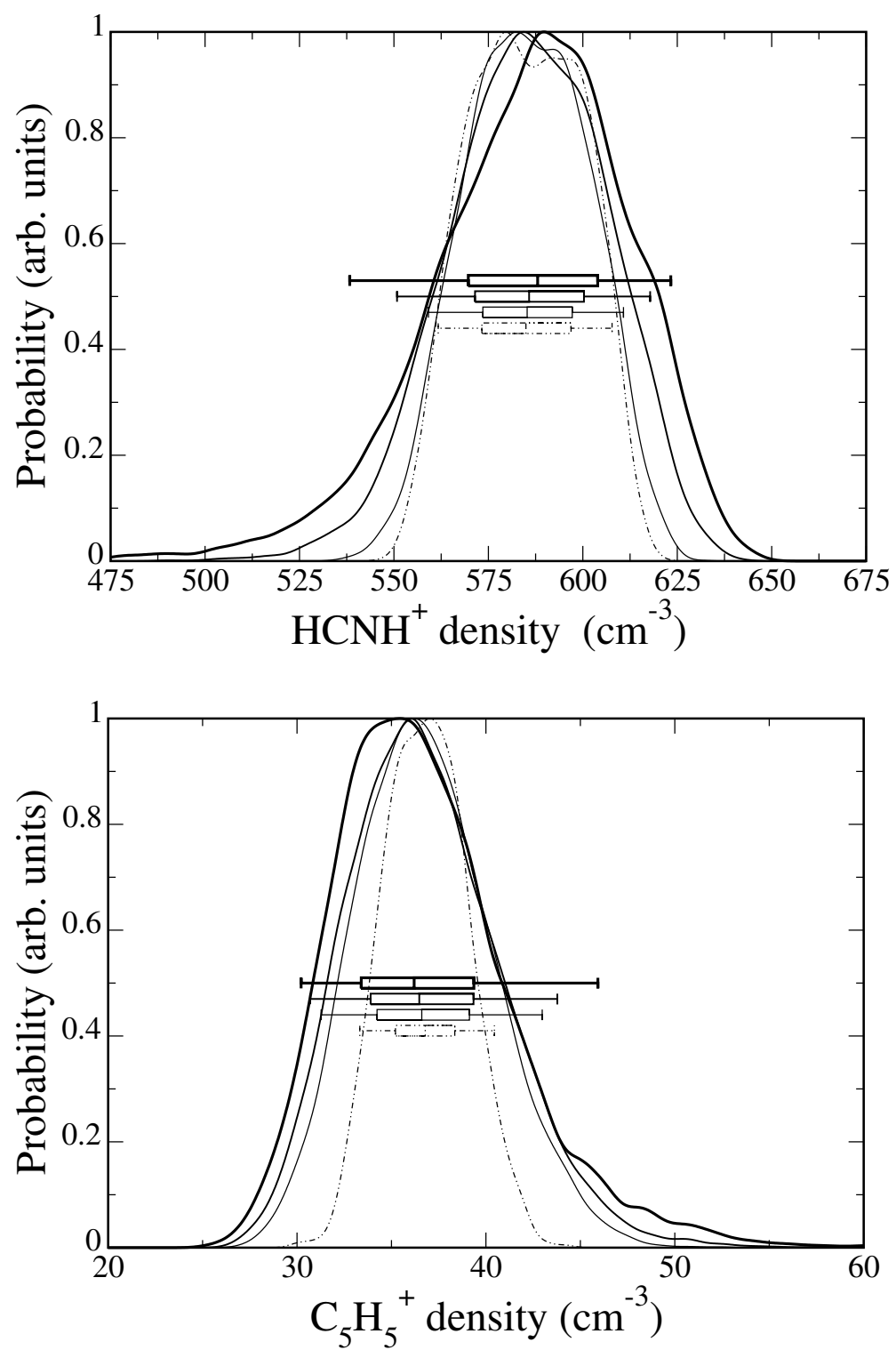

Figure 6: $\mathrm{HCNH}^{+}$and $\mathrm{C}_{5} \mathrm{H}_{5}^{+}$density distributions at $1200 \mathrm{~km}$ for night-time chemistry: with no (dashed line) / 25\% (thin line) / 50\% (normal line) / 75\% (thick line) relative uncertainty on the branching ratios. Horizontal boxplots depict the 5/25/50/75/95 quantiles. 


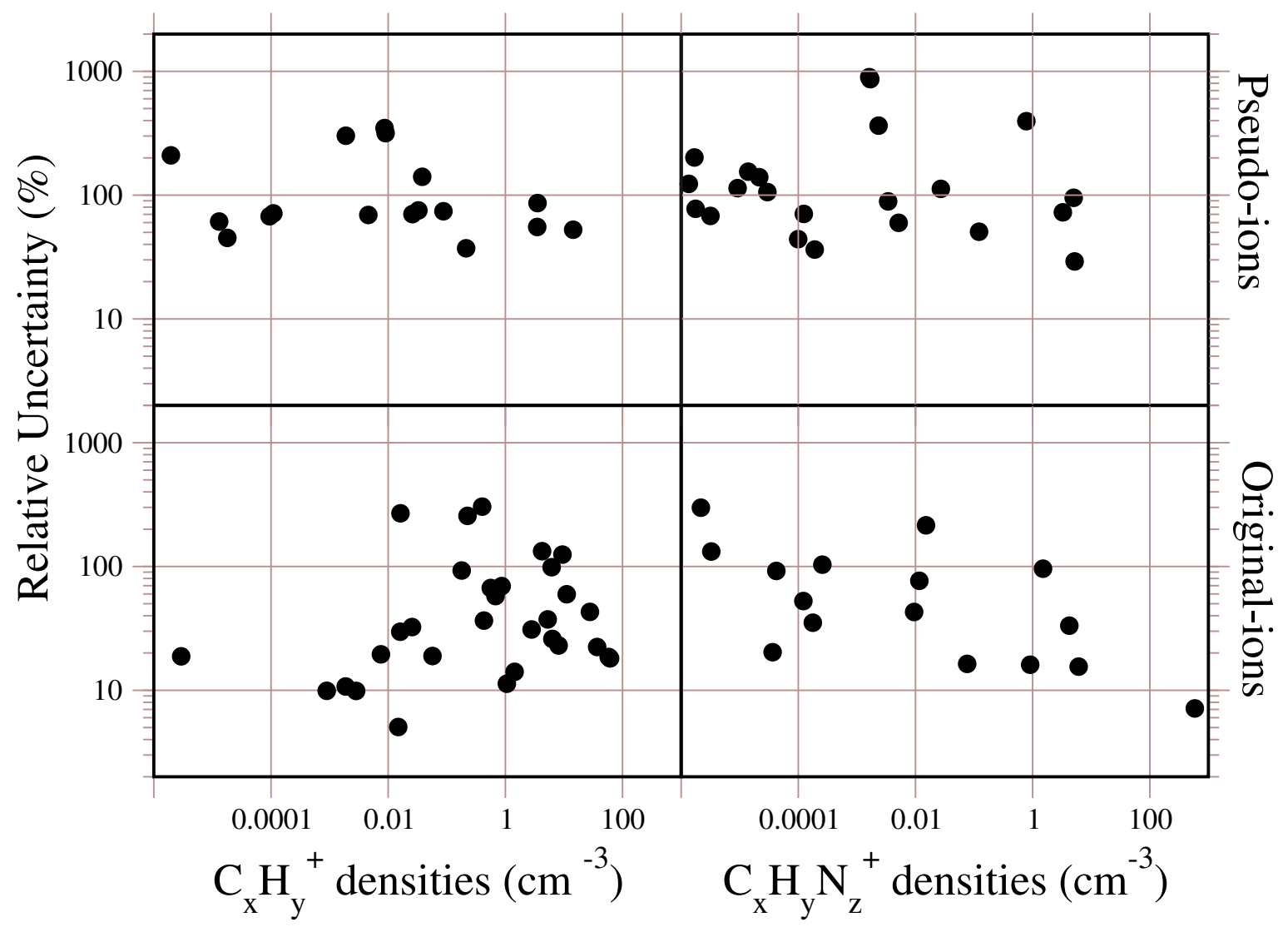

Figure 7: Relative uncertainties versus ion densities at $1200 \mathrm{~km}$ of altitude by night-time chemistry. 


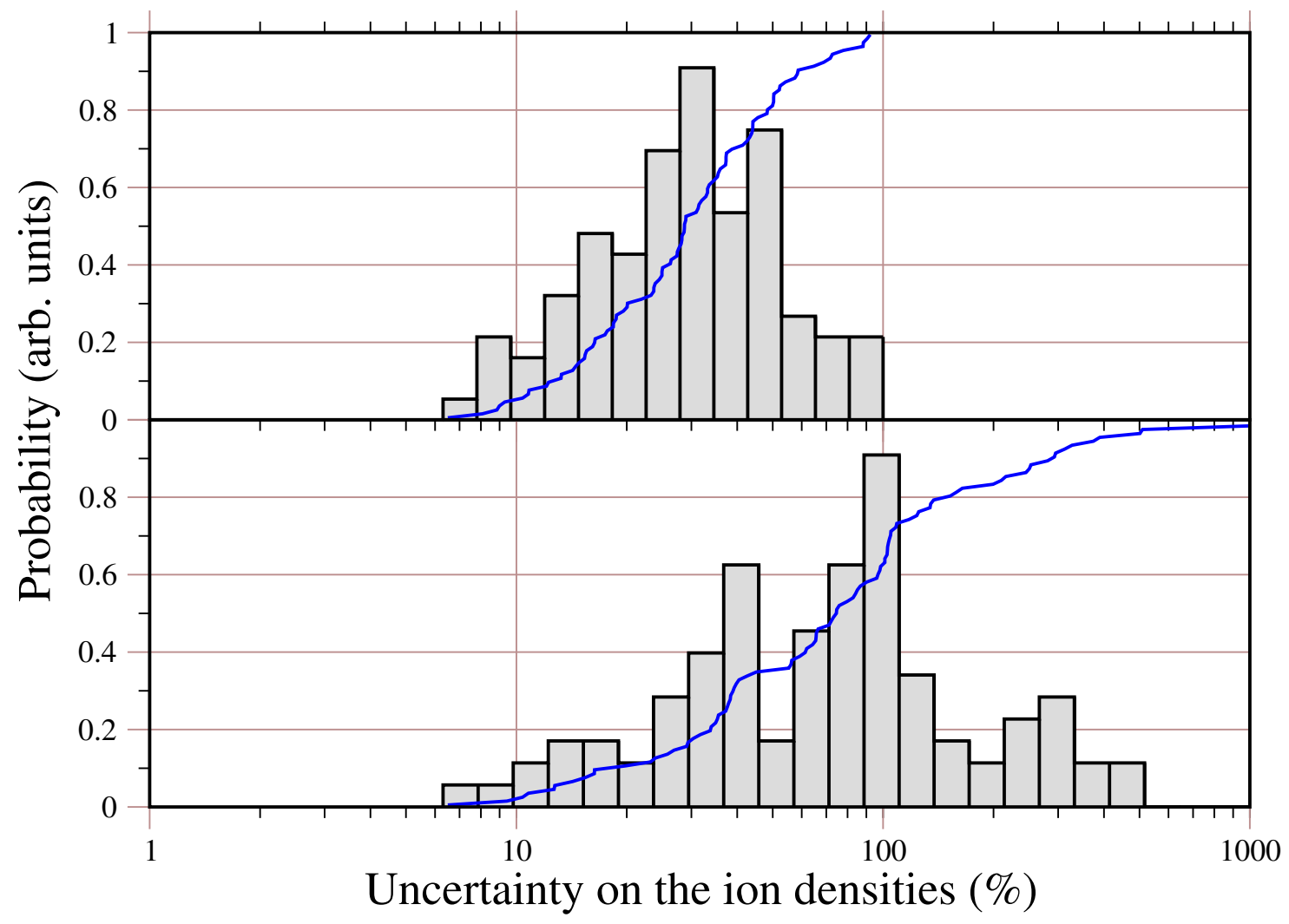

Figure 8: Distribution of the uncertainties for all ions densities. The full line represents the sample cumulative density function. The simulations were performed by night-time chemistry at $1000 \mathrm{~km}$ of altitude for two cases of uncertainty on the branching ratios: (above) no uncertainty ; (below) $50 \%$ relative uncertainty. 


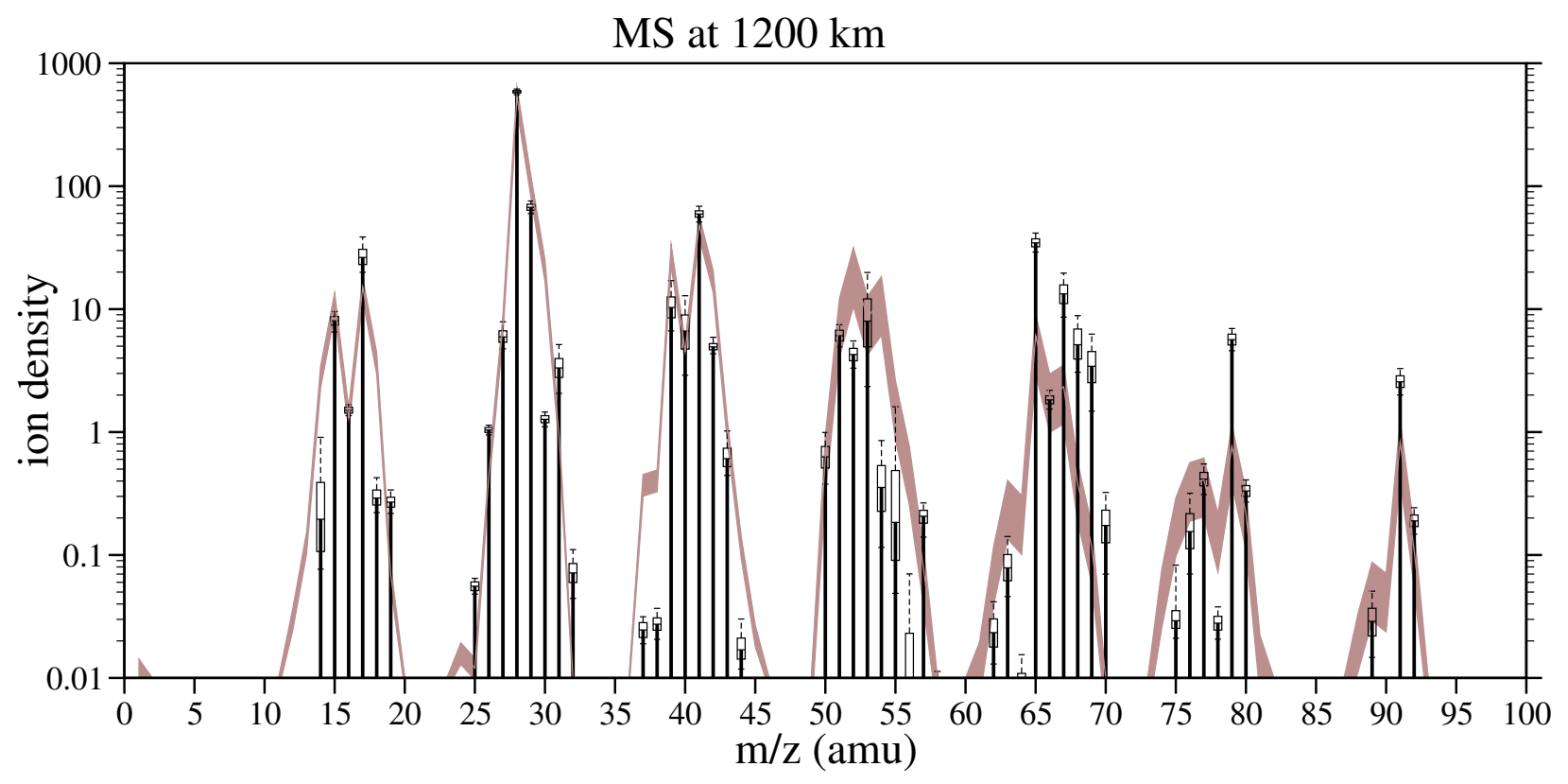

Figure 9: Simulated (drop lines) and measured (envelope) mass spectra of Titan ionosphere at $1200 \mathrm{~km}$ of altitude by night time. Box-plots and error bars correspond to confidence intervals of $50 \%$ and $90 \%$ for the calculated mass spectrum. Vertical boxplots depict the $5 / 25 / 50 / 75 / 95$ quantiles. 


\section{List of Tables}

1 Original and reviewed (bold) reaction rates for two well studied ion-molecule reactions. Rate constants are in $10^{-9} \mathrm{~cm}^{3} \cdot \mathrm{s}^{-1}$. . . . . . . . . . . . .

2 Comparison between branching ratios $\left(b_{i}\right)$ determinations for the $\mathrm{N}^{+}+\mathrm{CH}_{4}$ and the $\mathrm{N}_{2}^{+}+\mathrm{CH}_{4}$ reactions. The relative dispersion of the measurements and preferred values are in bold type. . . . . . . . . . . . . . . . .

3 Partial relative uncertainties resulting from a Dirichlet distribution elicited from two different global relative uncertainties. . . . . . . . . . . . . 58

4 Relative uncertainties for $\mathrm{HCNH}^{+}$and $\mathrm{C}_{5} \mathrm{H}_{5}^{+}$as a function of the postulated uncertainty about branching ratios. . . . . . . . . . . . . . 59

5 Uncertainty on the ten most abundant ions by night-time chemistry in Titan

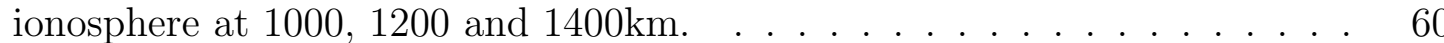




\begin{tabular}{|c|c|c|c|}
\hline Reference & Method & $k$ & $\Delta k$ \\
\hline \multicolumn{4}{|c|}{$\overline{\mathrm{N}^{+}+\mathrm{CH}_{4}}$} \\
\hline Rowe et al. (1985) & CRESU $(\mathrm{T}=8 \mathrm{~K})$ & 0.82 & 0.25 \\
\hline Dheandhanoo et al. (1984) & DT & 0.94 & 0.09 \\
\hline Adams et al. (1980) & SIFT & 1.38 & - \\
\hline Tichy et al. (1979) & SIFT & 1.1 & - \\
\hline Smith et al. (1978) & SIFT & 0.94 & 0.20 \\
\hline Anicich et al. (1977) & ICR & 1.35 & 0.13 \\
\hline Huntress (1977) & ICR & 1.35 & 0.15 \\
\hline Anicich (1993) & & \multicolumn{2}{|c|}{$1.15 \pm 15 \%$} \\
\hline \multicolumn{4}{|c|}{$\overline{\mathrm{N}_{2}^{+}+\mathrm{CH}_{4}}$} \\
\hline Randeniya and Smith (1991) & $(\mathrm{T}=8-15 \mathrm{~K})$ & 1.9 & 0.9 \\
\hline Rowe et al. (1989) & CRESU $(\mathrm{T}=70 \mathrm{~K})$ & 1.2 & 0.4 \\
\hline Smith et al. (1978) & SIFT & 1.0 & - \\
\hline Smith et al. (1978) & ICR & 0.98 & - \\
\hline Tichy et al. (1979) & ICR & 1.3 & - \\
\hline Anicich (1993) & & 1.14 & $5 \%$ \\
\hline
\end{tabular}

Table 1: Original and reviewed (bold) reaction rates for two well studied ion-molecule reactions. Rate constants are in $10^{-9} \mathrm{~cm}^{3} . \mathrm{s}^{-1}$. 


\begin{tabular}{|c|c|c|c|c|}
\hline \multicolumn{5}{|c|}{$\mathrm{N}^{+}+\mathrm{CH}_{4}$} \\
\hline Reference & $b_{1}$ & $b_{2}$ & $b_{3}$ & $\overline{b_{4}}$ \\
\hline Anicich et al. (2004) & 0.38 & 0.03 & 0.15 & 0.44 \\
\hline McEwan et al. (1998) & 0.53 & 0.05 & 0.10 & 0.32 \\
\hline Dheandhanoo et al. (1984) & 0.52 & 0.06 & 0.09 & 0.33 \\
\hline Adams et al. (1980) & 0.51 & 0.03 & 0.06 & 0.40 \\
\hline Tichy et al. (1979) & 0.42 & 0.06 & 0.14 & 0.38 \\
\hline Anicich et al. (1977) & 0.53 & 0.04 & 0.10 & 0.32 \\
\hline$\Delta b_{i} /\left(2 \bar{b}_{i}\right)$ & $15 \%$ & $34 \%$ & $36 \%$ & $16 \%$ \\
\hline Anicich (1993) & 0.50 & 0.05 & 0.10 & 0.36 \\
\hline \multicolumn{5}{|c|}{$\overline{\mathrm{N}_{2}^{+}+\mathrm{CH}_{4}}$} \\
\hline Reference & $b_{1}$ & $b_{2}$ & $b_{3}$ & \\
\hline Nicolas et al. (2003) & 0.07 & 0.88 & 0.05 & \\
\hline McEwan et al. (1998) & 0.05 & 0.80 & 0.15 & \\
\hline$\Delta b_{i} /\left(2 \bar{b}_{i}\right)$ & $17 \%$ & $5 \%$ & $50 \%$ & \\
\hline Anicich et al. (2004) & 0.12 & 0.88 & - & \\
\hline Randeniya and Smith (1991) (30K) & 0.20 & 0.80 & - & \\
\hline Tichy et al. (1979) & 0.11 & 0.89 & - & \\
\hline Smith et al. (1978) & 0.07 & 0.93 & - & \\
\hline$\Delta b_{i} /\left(2 b_{i}\right)$ & $52 \%$ & $8 \%$ & - & \\
\hline Anicich (1993) & 0.09 & 0.91 & - & \\
\hline
\end{tabular}

Table 2: Comparison between branching ratios $\left(b_{i}\right)$ determinations for the $\mathrm{N}^{+}+\mathrm{CH}_{4}$ and the $\mathrm{N}_{2}^{+}+\mathrm{CH}_{4}$ reactions. The relative dispersion of the measurements and preferred values are in bold type. 


\begin{tabular}{ccc}
\hline $\bar{b}_{i}$ & \multicolumn{2}{c}{$\hat{x}_{i}$} \\
\hline & $x=0.25$ & $x=0.75$ \\
\hline 0.5 & 0.19 & 0.56 \\
0.05 & 0.82 & 2.46 \\
0.1 & 0.56 & 1.69 \\
0.36 & 0.25 & 0.75 \\
\hline
\end{tabular}

Table 3: Partial relative uncertainties resulting from a Dirichlet distribution elicited from two different global relative uncertainties. 


\begin{tabular}{ccccc}
\hline \multicolumn{5}{c}{ Uncertainty on $b_{i}$} \\
\hline Ion & none & $25 \%$ & $50 \%$ & $75 \%$ \\
\hline $\mathrm{HCNH}^{+}$ & $10 \%$ & $12 \%$ & $12 \%$ & $14 \%$ \\
$\mathrm{C}_{5} \mathrm{H}_{5}^{+}$ & $26 \%$ & $34 \%$ & $34 \%$ & $38 \%$ \\
\hline
\end{tabular}

Table 4: Relative uncertainties for $\mathrm{HCNH}^{+}$and $\mathrm{C}_{5} \mathrm{H}_{5}^{+}$as a function of the postulated uncertainty about branching ratios. 


\begin{tabular}{|c|c|c|c|c|c|}
\hline \multicolumn{2}{|c|}{$1000 \mathrm{~km}$} & \multicolumn{2}{|c|}{$1200 \mathrm{~km}$} & \multicolumn{2}{|c|}{$1400 \mathrm{~km}$} \\
\hline Ions & $\frac{2 \sigma}{\overline{[I o n]}}$ & Ions & $\frac{2 \sigma}{\overline{[I o n]}}$ & Ions & $\frac{2 \sigma}{\overline{\mid I I o n]}}$ \\
\hline $\mathrm{HCNH}^{+}$ & $12 \%$ & $\mathrm{HCNH}^{+}$ & $7 \%$ & $\mathrm{HCNH}^{+}$ & $14 \%$ \\
\hline $\mathrm{C}_{5} \mathrm{H}_{5} \mathrm{~N}^{+}$ & $32 \%$ & $\mathrm{C}_{3} \mathrm{H}_{5}^{+}$ & $18 \%$ & $\mathrm{C}_{2} \mathrm{H}_{5}^{+}$ & $16 \%$ \\
\hline $\mathrm{C}_{7} \mathrm{H}_{7}^{+}$ & $34 \%$ & $\mathrm{C}_{2} \mathrm{H}_{5}^{+}$ & $19 \%$ & $\mathrm{CH}_{5}^{+}$ & $33 \%$ \\
\hline $\mathrm{C}_{5} \mathrm{H}_{5}^{+}$ & $35 \%$ & $\mathrm{C}_{5} \mathrm{H}_{5}^{+}$ & $22 \%$ & $\mathrm{C}_{3} \mathrm{H}_{5}^{+}$ & $17 \%$ \\
\hline $\mathrm{C}_{4} \mathrm{H}_{3}^{+}$ & $29 \%$ & $\mathrm{CH}_{5}^{+}$ & $43 \%$ & $\mathrm{CH}_{3}^{+}$ & $24 \%$ \\
\hline $\mathrm{C}_{5} \mathrm{H}_{7}^{+}$ & $56 \%$ & $\mathrm{C}_{5} \mathrm{H}_{7}^{+}$ & $52 \%$ & $\mathrm{~N}_{2}^{+}$ & $16 \%$ \\
\hline $\mathrm{C}_{3} \mathrm{H}_{5}^{+}$ & $20 \%$ & $\mathrm{C}_{3} \mathrm{H}_{3}^{+}$ & $60 \%$ & $\mathrm{C}_{2} \mathrm{H}_{3}^{+}$ & $32 \%$ \\
\hline $\mathrm{C}_{6} \mathrm{H}_{7}^{+}$ & $66 \%$ & $\mathrm{C}_{4} \mathrm{H}_{5}^{+}$ & $125 \%$ & $\mathrm{CH}_{4}^{+}$ & $16 \%$ \\
\hline $\mathrm{C}_{4} \mathrm{H}_{6} \mathrm{~N}^{+}$ & $73 \%$ & $\mathrm{CH}_{3}^{+}$ & $23 \%$ & $\mathrm{C}_{3} \mathrm{H}_{3}^{+}$ & $47 \%$ \\
\hline $\mathrm{C}_{2} \mathrm{H}_{5}^{+}$ & $24 \%$ & $\mathrm{C}_{4} \mathrm{H}_{3}^{+}$ & $26 \%$ & $\mathrm{C}_{2} \mathrm{H}_{4}^{+}$ & $174 \%$ \\
\hline
\end{tabular}

Table 5: Uncertainty on the ten most abundant ions by night-time chemistry in Titan ionosphere at 1000, 1200 and $1400 \mathrm{~km}$. 